\title{
Large-Eddy Simulation of Flow and Pollutant Transports in and Above Two-Dimensional Idealized Street Canyons
}

\author{
W. C. Cheng • Chun-Ho Liu
}

Received: 3 March 2010 / Accepted: 27 December 2010 / Published online: 15 January 2011

(C) The Author(s) 2011. This article is published with open access at Springerlink.com

\begin{abstract}
A large-eddy simulation (LES) model, using the one-equation subgrid-scale (SGS) parametrization, was developed to study the flow and pollutant transport in and above urban street canyons. Three identical two-dimensional (2D) street canyons of unity aspect ratio, each consisting of a ground-level area source of constant pollutant concentration, are evenly aligned in a cross-flow in the streamwise direction $x$. The flow falls into the skimming flow regime. A larger computational domain is adopted to accurately resolve the turbulence above roof level and its influence on the flow characteristics in the street canyons. The LES calculated statistics of wind and pollutant transports agree well with other field, laboratory and modelling results available in the literature. The maximum wind velocity standard deviations $\sigma_{i}$ in the streamwise $\left(\sigma_{u}\right)$, spanwise $\left(\sigma_{v}\right)$ and vertical $\left(\sigma_{w}\right)$ directions are located near the roof-level windward corners. Moreover, a second $\sigma_{w}$ peak is found at $z \approx 1.5 h$ ( $h$ is the building height) over the street canyons. Normalizing $\sigma_{i}$ by the local friction velocity $u_{*}$, it is found that $\sigma_{u} / u_{*} \approx 1.8, \sigma_{v} / u_{*} \approx 1.3$ and $\sigma_{w} / u_{*} \approx 1.25$ exhibiting rather uniform values in the urban roughness sublayer. Quadrant analysis of the vertical momentum flux $u^{\prime \prime} w^{\prime \prime}$ shows that, while the inward and outward interactions are small, the sweeps and ejections dominate the momentum transport over the street canyons. In the $x$ direction, the two-point correlations of velocity $R_{v, x}$ and $R_{w, x}$ drop to zero at a separation larger than $h$ but $R_{u, x}(=0.2)$ persists even at a separation of half the domain size. Partitioning the convective transfer coefficient $\Omega_{T}$ of pollutant into its removal and re-entry components, an increasing pollutant re-entrainment from 26.3 to $43.3 \%$ in the $x$ direction is revealed, suggesting the impact of background pollutant on the air quality in street canyons.
\end{abstract}

Keywords Large-eddy simulation · Pollutant removal - Quadrant analysis · Turbulence . Urban street canyons

W. C. Cheng · C.-H. Liu $(\bowtie)$

Department of Mechanical Engineering, The University of Hong Kong, 7/F, Haking Wong Building,

Pokfulam Road, Hong Kong, China

e-mail: liuchunho@graduate.hku.hk 


\section{Introduction}

Street canyons are the basic building units comprising the urban canopy layer (Oke 1976). An idealized two-dimensional (2D) street canyon usually serves as the platform that elucidates the fundamental mechanisms of ventilation and pollutant removal in urban areas. Oke (1988) classified the flow patterns in a 2D street canyon into three characteristic regimes, namely, isolated roughness, wake interference and skimming flow, according to the building-height-to-street-width (aspect) ratio $h / b$. The skimming flow regime, representing the characteristic airflow in a street surrounded by high-rise buildings $(h / b \geq 0.7)$ is our major concern nowadays. Inside the street canyons, the recirculating flow is driven by the shear of the prevailing wind aloft. Owing to the isolated nature of the recirculations, the pollutant removal from the street canyons is governed by turbulence, leading to a prolonged pollutant residence and elevated pedestrian-level pollutant concentrations.

Field measurements, physical modelling and numerical simulation are techniques commonly used for air pollution studies in urban street canyons. Field data are obtained directly, although the coverage of monitoring stations is limited due to the costly installation and operation. Moreover, it is sometimes difficult to differentiate the contributions from individual factors (e.g. wind speed and thermal stability). By measuring the nitrogen oxides $\left(\mathrm{NO}_{\mathrm{x}}\right)$ concentrations in three streets in Copenhagen, Berkowicz et al. (1996) found that the pollutant concentrations on the leeward side are higher than those on the windward side. This characteristic pollutant distribution is consistent with the airflow in the skimming flow regime in which the ground-level emissions are carried by the primary recirculation toward the leeward side. Afterward, Louka et al. $(1998,2000)$ measured the wind speed and direction, and the turbulence in between two pitched-roof buildings. The airflow inside the street canyons was found to be intermittent, suggesting occurrences of flapping (Belcher 2005) and the KelvinHelmholtz instability (Chandrasekhar 1981) of the roof-level shear layer. On the other hand, measurements in Oklahoma City showed that an array of heterogeneous buildings promotes turbulence levels (Nelson et al. 2007). The building geometry is thus a major factor affecting the ventilation and pollutant removal in street canyons.

Physical modelling is the problem diagnosis using reduced-scale models in wind tunnels or water channels. Under laboratory conditions, most of the testing parameters and sampling points are fully controllable but the large-scale atmospheric turbulence is hardly replicated. The discrepancy in that regard was demonstrated by Meroney et al. (1996) in which the flow dynamics and pollutant dispersion in an isolated street canyon are different from their periodic counterparts. Roughness elements are therefore usually included in wind-tunnel experiments simulating an urban environment. Pavageau and Schatzmann (1999) performed another wind-tunnel experiment to study the pollutant removal mechanism in periodic $2 \mathrm{D}$ street canyons. Using 49 and 21 sampling points, respectively, inside and above the sample street canyon, the spatial distributions of the mean and fluctuating pollutant concentrations on the vertical centreplane were measured. On the other hand, using naphthalene sublimation in a wind tunnel, Barlow and Belcher (2002) determined the convective transfer coefficient $\Omega_{T}$ of a pollutant to compare the pollutant removal rates of street canyons of different aspect ratios. In the wake interference regime $(0.4<h / b<0.7), \Omega_{T}$ increases with increasing aspect ratio that extends into the skimming flow regime $(h / b>0.7)$, and eventually peaks in the street canyon of aspect ratio between 0.6 and 0.8 . Besides, Li et al. (2008a) recently reported the mean and fluctuating velocities in street canyons of aspect ratio $0.5,1$ and 2 using water-channel experiments but pollutant dispersion was not included.

With rapidly improving computer power, computational fluid dynamics (CFD) has become a popular tool to study the air pollution in street canyons in the last decade. The 
Reynolds-averaged Navier-Stokes (RANS) equations with the $k-\varepsilon$ turbulence model and the large-eddy simulation (LES) are mostly used in the community. The CFD studies for street canyons, including their merits and key findings, are summarized elsewhere (Vardoulakis et al 2003; Li et al. 2006). Unlike field or laboratory measurements, the variables in CFD are calculated in the form of spatio-temporal functions, and CFD is often used to examine the fundamental transport mechanisms since idealized conditions can be fully implemented in sensitivity tests. To ensure modelling accuracy, validating the CFD results with experimental data are necessary. Liu and Barth (2002) detailed the turbulence and pollutant statistics in an idealized street canyon of unity aspect ratio using LES. Afterwards, Liu et al. (2005) proposed the air exchange rate $(\mathrm{ACH})$ and the pollutant exchange rate $(\mathrm{PCH})$ to compare the performance of ventilation and pollutant removal, respectively, in street canyons of aspect ratio 0.5, 1 and 2. On the other hand, Cui et al. (2004) applied the quadrant analysis to determine the scales of the momentum transport at the roof level of street canyons. Although frequent ejections are weak, a few strong sweeps dominate the momentum transport. Next, Letzel et al. (2008) used the parallelized LES code PALM to study urban turbulence structures in which the Kelvin-Helmholtz instability was identified atop a street canyon. Cai et al. (2008) examined the characteristic pollutant removal from street canyons of aspect ratio 1/3, 2/3, 1, 3/2 and 2 with line or area pollutant sources. Recently, Li et al. (2008a) studied momentum and pollutant transport in deep street canyons of aspect ratio 3 and 5, which are commonly found in dense compact cities across the world. Apart from isothermal conditions, the number of large-eddy simulations investigating the effects of unstable stratification on the microscale climate in street canyons is increasing (Cai 2009; Li et al. 2009, 2010; Park and Baik 2009).

Most of the aforementioned studies, either experimental or computational, have focused only on the flow dynamics and pollutant transport inside or along the roof level of one single street canyon. As such, we extended our LES covering the shear layer over the street canyons using an approach analogous to that in Kanda et al. (2004) and Coceal et al. (2007). The major advancement in our study is that the flows inside the street canyons are well resolved at a higher spatial resolution. The specific objectives are use of LES to elucidate the turbulent transport processes of wind and pollutant, and their interactions both inside and above the street canyons in detail. The results should enrich the fundamental understanding of ventilation and pollutant removal in cities in the current era of rapid urbanization.

\section{Methodology}

The open-source CFD code OpenFOAM 1.5 (OpenFOAM 2009) was used in the LES in this study. The detailed numerical methodology is reported below.

\subsection{Governing Equations}

In the LES, the flow variables are decomposed into the resolved-scale components (represented by overlines) and the subgrid-scale (SGS) components using a filtering operation. The filtered continuity equation

$$
\frac{\partial \bar{u}_{i}}{\partial x_{i}}=0
$$

and the filtered momentum equation

$$
\frac{\partial \bar{u}_{i}}{\partial t}+\frac{\partial}{\partial x_{j}} \bar{u}_{i} \bar{u}_{j}=-\Delta P \delta_{i 1}-\frac{\partial \bar{p}}{\partial x_{i}}-\frac{\partial \tau_{i j}}{\partial x_{j}}+v \frac{\partial^{2} \bar{u}_{i}}{\partial x_{j} \partial x_{j}}
$$


were solved where $\bar{u}_{i}$ are the resolved-scale velocity vectors, $\bar{p}$ is the resolved-scale kinematic pressure, $v$ is the kinematic viscosity, $\Delta P$ is the difference in large-scale kinematic pressure, and $\delta_{i j}$ is the Kronecker delta. The SGS stresses $\tau_{i j}$ were modelled in the form

$$
\tau_{i j}=-2 v_{S G S} S_{i j}
$$

where $v_{S G S}\left(=C_{k} k_{S G S}^{1 / 2} \Delta\right)$ is the kinematic eddy viscosity, $S_{i j}\left(=0.5\left[\partial \bar{u}_{i} / \partial x_{j}+\partial \bar{u}_{j} / \partial x_{i}\right]\right)$ is the strain-rate tensor, $\Delta\left(=\left[\Delta_{1} \Delta_{2} \Delta_{3}\right]^{1 / 3}\right)$ is the filter width, and $C_{k}(=0.07)$ is the modelling constant. The one-equation SGS model (Schumann 1975) was employed in which the SGS turbulence kinetic energy (TKE) $k_{S G S}$ conservation was calculated by solving its transport equation

$$
\frac{\partial k_{S G S}}{\partial t}+\frac{\partial}{\partial x_{i}} k_{S G S} \bar{u}_{i}=2 v_{S G S} S_{i j} S_{i j}+\left(v+v_{S G S}\right) \frac{\partial^{2} k_{S G S}}{\partial x_{i} \partial x_{i}}-C_{\varepsilon} \frac{k_{S G S}^{3 / 2}}{\Delta}
$$

where $C_{\varepsilon}(=1.05)$ is the modelling constant. The filtered scalar transport equation

$$
\frac{\partial \bar{c}}{\partial t}+\frac{\partial}{\partial x_{i}} \bar{c} \bar{u}_{i}=-\frac{\partial \gamma_{i}}{\partial x_{i}}+\frac{v}{S c} \frac{\partial^{2} \bar{c}}{\partial x_{i} \partial x_{i}}
$$

was solved where $\bar{c}$ is the resolved-scale pollutant concentration and $S c(=0.72)$ is the Schmidt number. The SGS pollutant flux $\gamma_{i}$ was modelled in the form

$$
\gamma_{i}=-\frac{\nu_{\mathrm{SGS}}}{\mathrm{Sc}} \frac{\partial \bar{c}}{\partial x_{i}}
$$

\subsection{Wall Model}

The law of the wall due to Spalding (1962), which is applicable in entire laminar and turbulent flow regimes, was used to model the near-wall flows in the LES because the transport process in the domain core is our key concern. It is implemented mathematically solving

$$
z^{+}=u^{+}+\frac{1}{E}\left\{e^{\kappa u^{+}}-\left[1+\kappa u^{+}+\frac{1}{2}\left(\kappa u^{+}\right)^{2}+\frac{1}{6}\left(\kappa u^{+}\right)^{3}\right]\right\}
$$

where $u_{\tau}$ ( $=\sqrt{\tau_{w} / \rho}, \tau_{w}$ is the wall shear stress and $\rho$ is the fluid density) is the wall friction velocity, $z^{+}=u_{\tau} z_{\perp} / \nu, u^{+}=\bar{u}_{\|} / u_{\tau}$, where $z_{\perp}$ is the wall-normal distance, $\bar{u}_{\|}$is the resolved-scale velocity component parallel to the wall, $\kappa(=0.42)$ is the von Kármán constant, and $E(=9.0)$ is the empirical modelling constant. Equation (7) in turn implies that

$$
u^{+}= \begin{cases}z^{+} & \text {if } z^{+} \text {is small (laminar sublayer) } \\ \frac{1}{\kappa} \ln \left(E z^{+}\right) & \text {if } z^{+} \text {is large (logarithmic region) }\end{cases}
$$

which is consistent with the standard wall treatment (Launder and Spalding 1974). Equations (7) and (8) are solved iteratively for $u_{\tau}$, which is then used to calculate $v_{S G S}$ using

$$
v_{S G S}=\frac{u_{\tau}^{2}}{\left|\nabla \bar{u}_{||} \cdot \hat{n}\right|}-v,
$$

where $\hat{n}$ is the wall-normal unit vector. 


\subsubsection{Pollutant}

The pollutant flux from the ground source is calculated from

$$
c^{\prime \prime} w^{\prime \prime} \text { ground }=\left(\frac{v+v_{S G S}}{\mathrm{Sc}}\right) \frac{\Delta c}{\Delta z_{\perp}}
$$

where $\Delta c$ is the pollutant concentration difference and $\Delta z_{\perp}$ is the spacing between the ground and the first grid point above the ground.

\subsection{Computational Domain and Boundary Conditions}

The computational domain consisted of three identical idealized 2D street canyons of unity aspect ratio $(h=b)$ that are placed beneath the shear layer of height $h_{f}(=5 h ;$ Fig. 1$)$. For the flow variables, free-slip and no-slip boundaries are applied, respectively, at the top and on all the stationary walls. Periodic boundaries are used in the streamwise $x$ and spanwise $y$ directions. The prevailing flow in the shear layer is driven by the constant background pressure difference $\Delta P$ in the streamwise momentum equation. The turbulence activation time is $50 h / U_{f}$ achieving pseudo steady-state, where $U_{f}$ is the prevailing wind speed. Another period of time $50 h / U_{f}$ is used for data archive for the statistical analysis post-processing.

To model the pollutant sources, a constant pollutant concentration $C_{0}(=1)$ is prescribed on all the streets. No background pollutant is considered so the pollutant concentration is zero at the domain inlet. At the domain outlet, the open boundary condition for pollutant concentration

$$
\frac{\partial \bar{c}}{\partial t}+\bar{u} \frac{\partial \bar{c}}{\partial x}=0
$$

Spanwise boundaries (periodic boundaries), 6h spanwise

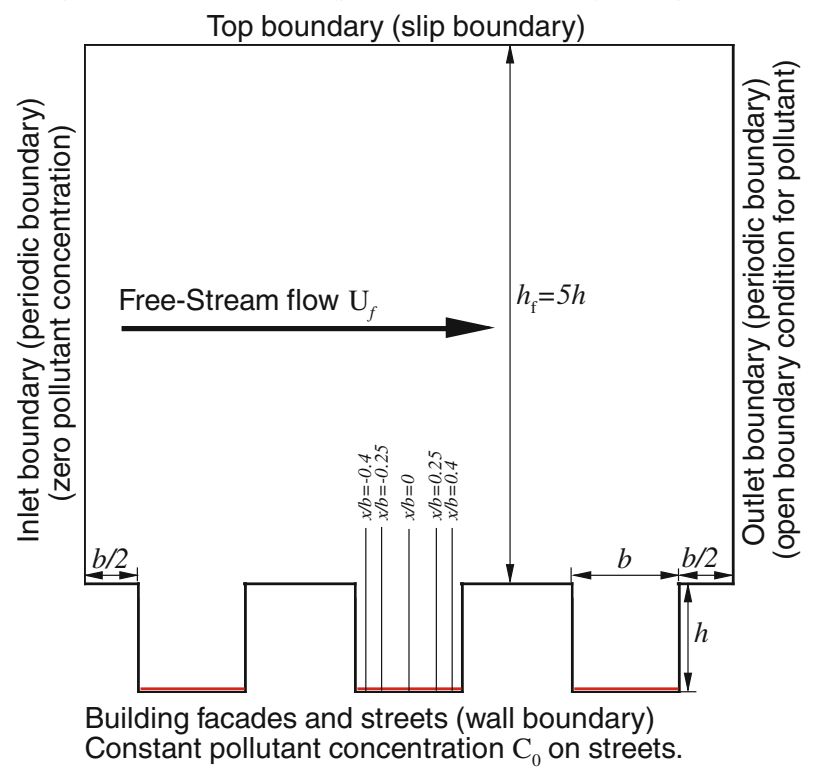

Fig. 1 Computational domain 
is used to prevent pollutant being reflected back into the domain. At the top and other solid boundaries, zero-gradient boundaries of pollutant are used so deposition is not considered.

The entire spatial domain is discretized into 13.5 million brick elements, in which 0.5 million and 12 million elements are used respectively, in each street canyon and the shear layer. The homogeneous spanwise extent is discretized uniformly at grid spacing $\Delta y=0.025 h$. Structured mesh with grid stretching in $x$ and $z$ directions is employed. A higher resolution, $0.014 h$, is used near the buildings and streets resolving the high gradients, and in light of the recirculation centre, the mesh resolution is relieved to $0.028 \mathrm{~h}$ in the central core of the street canyon. The mesh in the shear layer is further stretched in the $z$ direction in which the resolution equals $0.04 h$ at the domain top. The timestep increment is $0.005 h / U_{f}$ where $U_{f}$ is the prevailing wind speed. The Reynolds number $\operatorname{Re}\left(=U_{f} h / v\right)$ is 8,000. The resolvedscale variables $\bar{\phi}$ are decomposed into their mean $\langle\bar{\phi}\rangle$ and fluctuating $\phi^{\prime \prime}$ components (i.e. $\left.\bar{\phi}=\langle\bar{\phi}\rangle+\phi^{\prime \prime}\right)$, and the mean quantities, representing the ensemble average properties, are averaged in the homogeneous spanwise direction and the temporal domain. The turbulence statistics are further averaged based on the three identical street canyons. The computation was carried out on a Xeon 8-core machine and the wall clock computation time was about 1,000 hours.

\subsection{Numerical Method}

The finite volume method (FVM) was used to solve the transport equations. The secondorder-accurate backward differencing scheme was used in the time derivatives while the Gaussian integration with linear interpolation scheme (second-order-accurate central differencing) was used in the spatial derivatives. The pressure-implicit with splitting of operators (PISO) pressure-velocity coupling scheme was used in the pressure correction. The preconditioned conjugate gradient (PCG) method was used to solve the linear equation systems for $\bar{p}$ and the preconditioned bi-conjugate gradient (PBiCG) method for $\bar{u}_{i}, k_{S G S}$ and $\bar{c}$.

\section{Flow Field}

\subsection{Model Validation}

The vertical profiles of the resolved-scale mean velocities, TKE, and velocity skewness and kurtosis calculated by the current LES are compared with those of the wind-tunnel results of Brown et al. (2000) and the large-eddy simulation of Cui et al. (2004) in Figs. 2-5. Brown et al. (2000) carried out the experiment in the meteorological wind tunnel at the US Environmental Protection Agency. It consisted of six identical idealized 2D street canyons of unity aspect ratio assembled by seven identical building blocks of square cross-section $(0.15 \mathrm{~m} \times$ $3.8 \mathrm{~m} \times 0.15 \mathrm{~m}$ ). The turbulence statistics in the sixth street canyon, representing the fully developed wind profiles, were sampled. On the other hand, Cui et al. (2004) modified the Regional Atmospheric Modelling System (RAMS 2009), which was originally designed for mesoscale meteorological applications, to develop their LES model. The Smagorinsky eddyviscosity SGS model was used with a range of modelling constant values $\left(0.08 \leq C_{\varepsilon} \leq 0.12\right)$ depending on the locations in the street canyon. A smaller $C_{\varepsilon}$ is adopted inside the street canyon in order to reduce the unnecessary turbulence dissipation. The case CSV81 of Cui et al. (2004) is employed in the current model validation exercise. In the comparison of the mean velocities, both $\langle\bar{u}\rangle$ and $\langle\bar{w}\rangle$ are normalized by the average streamwise velocity $U_{s}$ at height $1 \leq z / h \leq 1.5$. As shown in Fig. 2, the current LES agrees well with the previous 

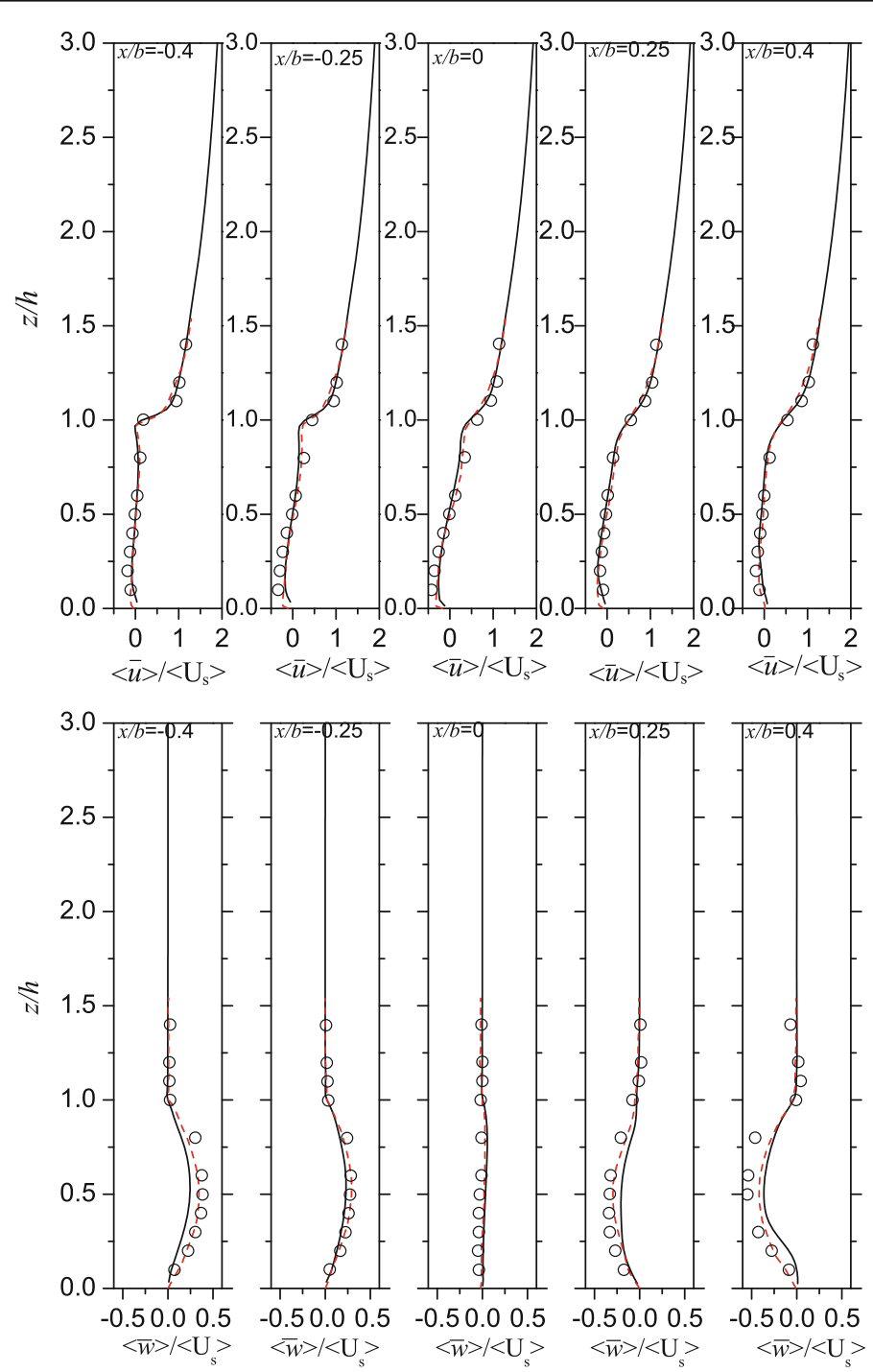

Fig. 2 Vertical profiles of $\mathbf{a}\langle\bar{u}\rangle$ and $\mathbf{b}\langle\bar{w}\rangle$ at $x / b=-0.4,-0.25,0,0.25$ and 0.4. Current LES: black solid line; Cui et al. (2004): red dashed line; and Brown et al. (2000): empty circle

LES (Cui et al. 2004) as well as the wind-tunnel experiment (Brown et al. 2000). A lower mean vertical velocity $\langle\bar{w}\rangle$ in the street canyon is observed in the LES compared with the wind-tunnel experiment (Fig. 2b). Cui et al. (2004) suggested that the difference is attributed to the shallow vertical extent of the computational domain and the coarse roof-level mesh resolution. The computational domain of the current LES $(6 h \times 5 h \times 6 h)$ is larger than that of (Cui et al., 2004, $2 h \times 3.25 h \times 2.25 h$ ), and three identical street canyons are considered in the current LES but only one in Cui et al. (2004). Besides, in the current LES, the mesh resolution is coarser (by 30\%) in the streamwise direction but is more refined (by 20\%) in the vertical direction near the roof level. Apparently, increasing the domain size and the spatial resolution cannot fully rectify the underpredicted mean vertical velocity in the street canyons. 

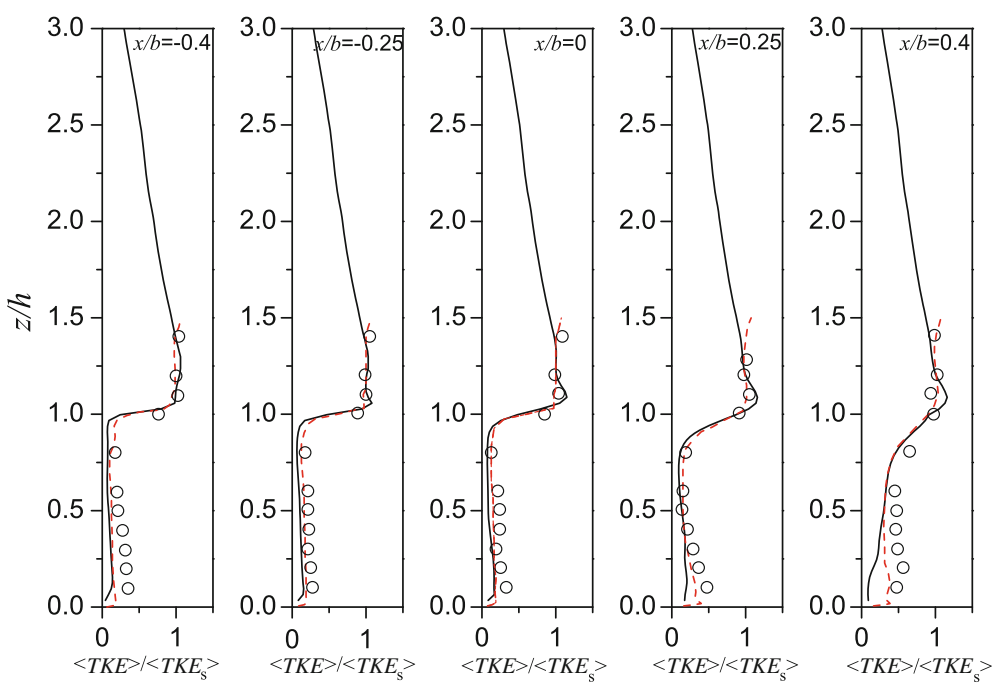

Fig. 3 Vertical profiles of $\langle T K E\rangle$ at $x / b=-0.4,-0.25,0,0.25$ and 0.4. Current LES: black solid line; Cui et al. (2004): red dashed line; and Brown et al. (2000): empty circle

A more detailed analysis is therefore required to examine the correlation among domain size, mesh resolution, and recirculating flow speed.

Similar to the mean velocities, $\langle T K E\rangle$ is normalized by $T K E_{s}$, which is its average at height $1.0 \leq z / h \leq 1.5$ over the street canyons (Fig. 3). A mild peak of $\langle T K E\rangle$ is observed right over the roof level in the current LES. Neither the LES CSV81 of Cui et al. (2004) nor the wind-tunnel experiment of Brown et al. (2000) showed a roof-level maximum. Indeed, the peak is found in other large-eddy simulations (Liu and Barth 2002; Li et al. 2008b) and in other cases of Cui et al. (2004) as well. Comparing with the wind-tunnel data, the TKE in the street canyon is underpredicted in both the current LES and Cui et al. (2004), in which large discrepancies are shown in the TKE profiles at $x / b=0.4$.

In addition to the mean velocities and the TKE, the skewness $s_{\phi}\left(=\left\langle\phi^{\prime \prime 3}\right\rangle / \sigma_{\phi}^{3}\right)$ and the kurtosis $k_{\phi}\left(=\left\langle\phi^{\prime \prime 4}\right\rangle / \sigma_{\phi}^{4}\right)$ of the streamwise $\left(s_{u}\right.$ and $\left.k_{u}\right)$ and vertical $\left(s_{w}\right.$ and $\left.k_{w}\right)$ velocities are calculated (Figs. 4, 5). Skewness and kurtosis measure the degree of the asymmetry and peakedness, respectively, of a probability distribution. For the normal distribution, the skewness is equal to zero and the kurtosis three. Similar patterns of $s_{u}$ are depicted in the LES of Cui et al. (2004) and the current LES (Fig. 4a). A mild peak $\left(s_{u}>0\right)$ is observed at the roof level of the street canyons demonstrating the asymmetric nature of the turbulence in strong shear. Besides, while moving toward the windward side from $x / b=-0.4$ to $x / b=0.4, s_{u}$ spreads out from a sharp peak to a broad one below the roof level. Though the peak is not clearly identified in the wind-tunnel experiment (likely due to the coarse sampling resolution), $s_{u}$ of the two large-eddy simulations fall within the data of Brown et al. (2000).

Similar to $s_{u}, k_{u}$ calculated by the two simulations are peaked near the roof level of the street canyon except at $x / b=0.4$ (Fig. 5a); the peak of $k_{u}$ is again not clearly resolved in the wind-tunnel experiment. While moving from $x / b=-0.4$ to 0.25 , the $k_{u}$ peak descends from over to below the roof level, and finally it is almost flat out at $x / b=0.4$. The more uniform $k_{u}$ on the windward side is probably caused by the downward wall jet of fresh air entrainment. The elevated roof-level $s_{u}$ and $k_{u}$ suggest that the probability distribution of the streamwise velocity deviates markedly from the normal distribution. In particular, the peaks 

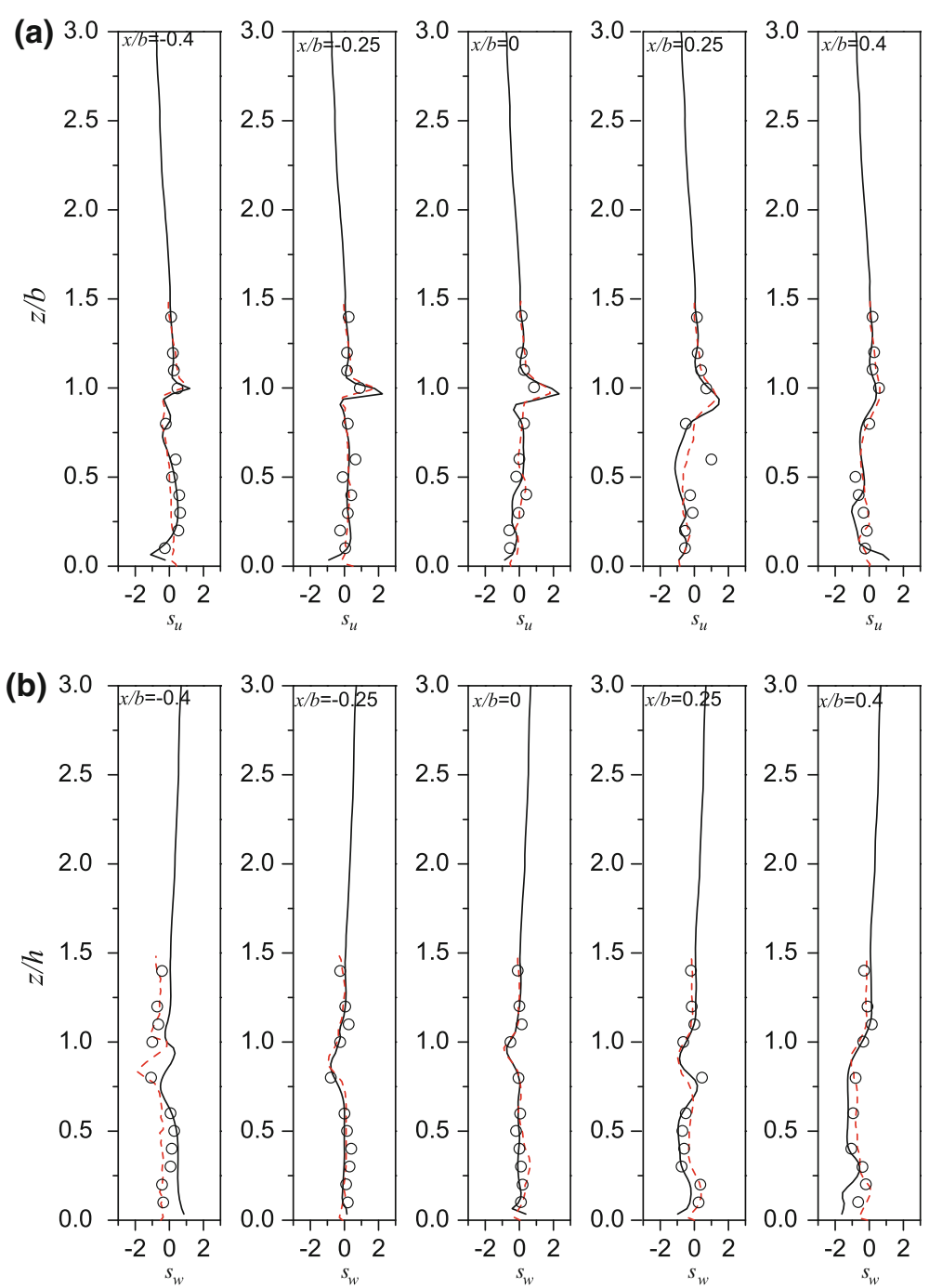

Fig. 4 Vertical profiles of $\mathbf{a} s_{u}$ and $\mathbf{b} s_{w}$ at $x / b=-0.4,-0.25,0,0.25$ and 0.4. Current LES: black solid line; Cui et al. (2004): red dashed line; and Brown et al. (2000): empty circle

are narrower with longer tails on the side $u^{\prime \prime}>0$. In the rest of the street canyon, $k_{u}$ scatters around three and $s_{u}$ around zero, implying that the mean streamwise velocity is normally distributed at large. The characteristic pattern of $k_{w}$ is not as obvious as its $k_{u}$ counterpart, though both the LES and wind-tunnel results fluctuate around three (Fig. 5b).

The current LES results are also compared with those of other LES (Liu et al. 2004; Li et al. 2008b) and a water-channel experiment (Li et al. 2008a). The vertical profiles of the mean wind $(\langle\bar{u}\rangle$ and $\langle\bar{w}\rangle)$ and wind standard deviations $\left(\sigma_{u}\right.$ and $\left.\sigma_{w}\right)$ are shown in Figs. 6 and 7 , respectively. The results are normalized by the free-stream speed $U_{f}$. Owing to different domain heights in the studies (Table 1), $U_{f}$ is taken at different heights. The channel height in the water-channel experiment ( $\mathrm{Li}$ et al. 2008a) is $5 h(=0.5 \mathrm{~m})$ and $U_{f}$ is taken at $3 h$. 

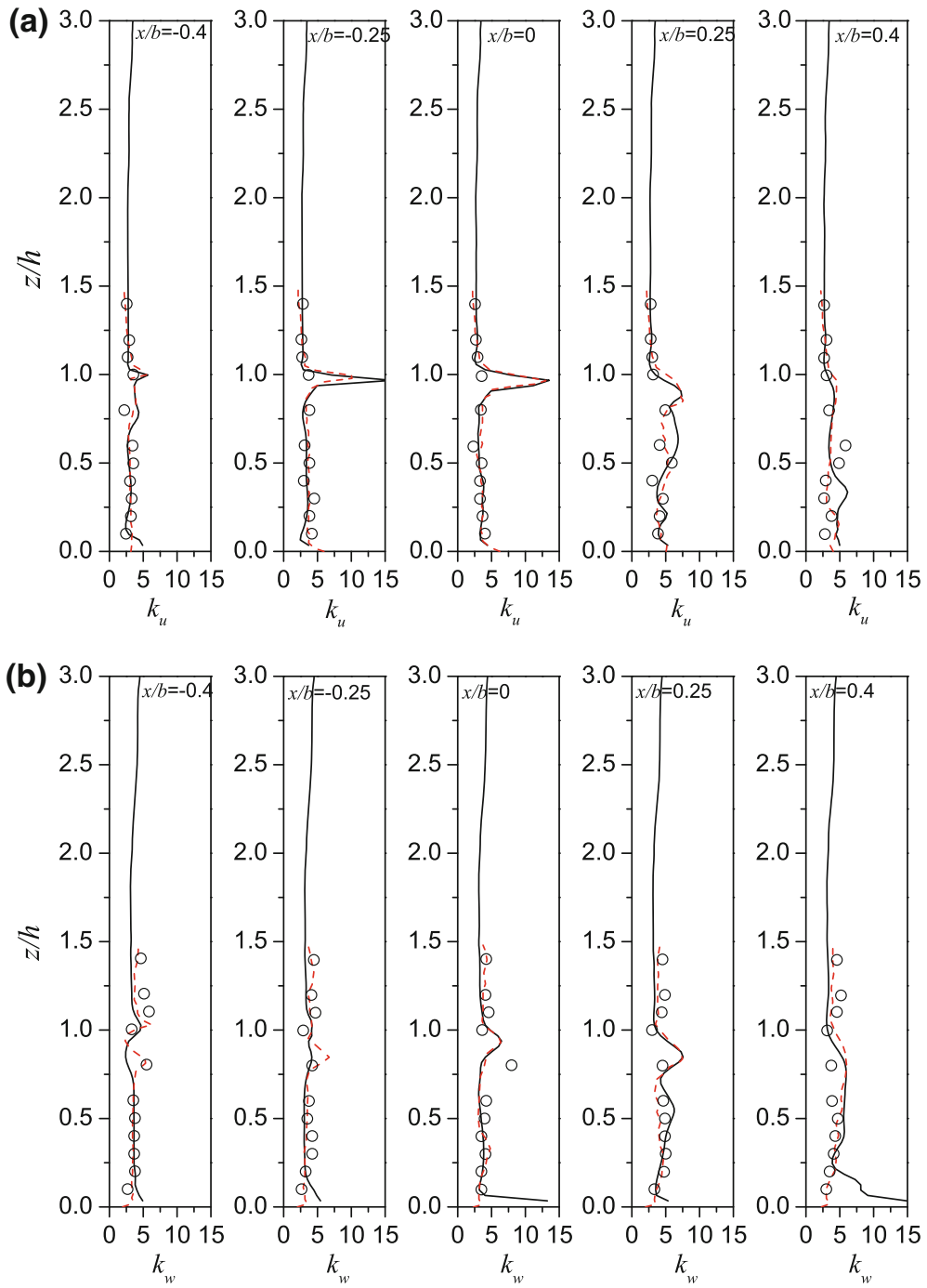

Fig. 5 Vertical profiles of $\mathbf{a} k_{u}$ and $\mathbf{b} k_{w}$ at $x / b=-0.4,-0.25,0,0.25$ and 0.4. Current LES: black solid line; Cui et al. (2004): red dashed line; and Brown et al. (2000): empty circle

Table 1 Height of computational domain

\begin{tabular}{ll}
\hline Studies & Height \\
\hline LES, one-equation —current LES & $6 h$ \\
LES, dynamic (Liu and Barth 2002) & $0.5 h$ \\
LES, one equation (Li et al. 2008a) & $1 h$ \\
Water channel experiment (Li et al. 2008b) & $3 h$
\end{tabular}

In the LES, $U_{f}$ is taken at the domain top. The results of $\langle\bar{u}\rangle$ and $\langle\bar{w}\rangle$ consistently depict the skimming flow patterns in a street canyon. The vertical profiles of $\langle\bar{w}\rangle / U_{f}$ at $x / b=0$ measured in the water channel of Li et al. (2008a) show larger magnitudes that are not observed 

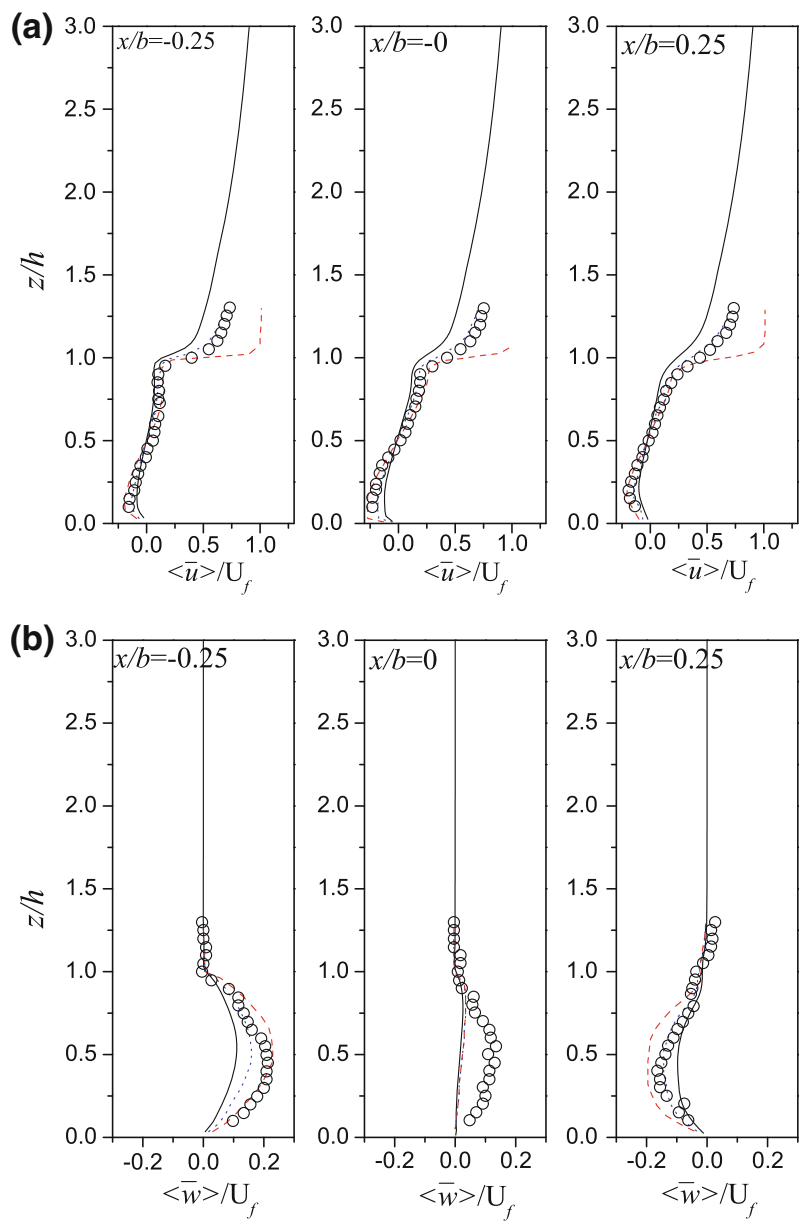

Fig. 6 Vertical profiles of $\mathbf{a}\langle\bar{u}\rangle$ and $\mathbf{b}\langle\bar{w}\rangle$ at $x / b=-0.25,0$ and 0.25. Current LES: black solid line; Liu et al. (2004): red dashed line; Li et al. (2008b): blue dotted line; and Li et al. (2008a): empty circle

in the wind-tunnel measurements of Brown et al. (2000), the LES of Cui et al. (2004) and the current LES. The difference may be due to the finite width of the water channel compared with the wider wind tunnel and the cyclic spanwise extent in the LES. Comparing the three sets of LES results, a higher roof-level wind speed is observed in the LES with a lower domain height. The shallower shear layer likely suppresses the wind-profile development over the buildings leading to a higher roof-level speed. Nonetheless, the LES calculated flow patterns agree with each other in principle.

The LES and water-channel results of $\sigma_{u}$ and $\sigma_{w}$ agree reasonably well in the street canyons (Fig. 7). Peaks of $\sigma_{w}$ are observed in the LES of Li et al. (2008a) and Liu et al. (2004) at the street canyon roof level, which, however, are not observed in the current LES. The peaks are more obvious in Liu et al. (2004), which is believed to be the result of the shallow shear layer employed in their LES. A shorter domain height increases the roof-level velocity gradient that in turn promotes the local turbulence production leading to the elevated $\sigma_{w}$. The enhanced roof-level turbulence is then carried by the primary recirculation into the street 

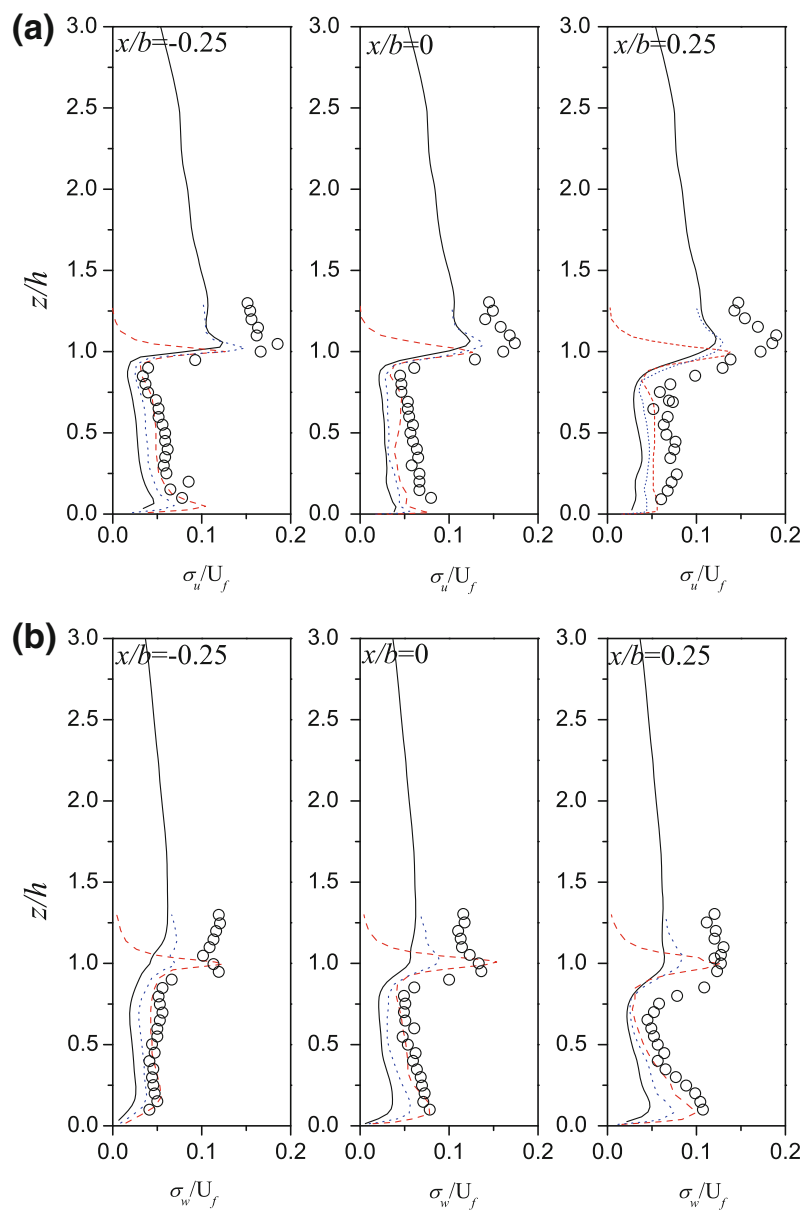

Fig. 7 Vertical profiles of $\mathbf{a} \sigma_{u}$ and $\mathbf{b} \sigma_{w}$ at $x / b=-0.25,0$ and 0.25. Current LES: black solid line; Liu et al. (2004): red dashed line; Li et al. (2008b): blue dotted line; and Li et al. (2008a): open circle

canyon. Hence, peaks of $\sigma_{w}$ are observed at the street level in the LES of Liu et al. (2004) and Li et al. (2008a).

\subsection{Standard Deviations of Wind Velocity $\sigma_{u}, \sigma_{v}$ and $\sigma_{w}$}

The spatial distributions of the velocity standard deviations, $\sigma_{u}, \sigma_{v}$ and $\sigma_{w}$, are depicted in Fig. 8; the maximum $\sigma_{u}$ and $\sigma_{v}$ are initiated, respectively, right over the street canyons and building roofs $(\leq 1.2 h)$. In $2 \mathrm{D}$ idealized street canyons, the roof-level vertical velocity fluctuation $w^{\prime \prime}$ contributes directly to the air exchange between the street canyon and the shear layer. A maximum $\sigma_{w}$ is observed near the roof-level windward corner where a vast air exchange takes place. Another $\sigma_{w}$ peak is developed at about $z=1.5 \mathrm{~h}$ in the shear layer, suggesting enhanced turbulence and pollutant mixing for $1.4 \mathrm{~h} \leq z \leq 1.6 \mathrm{~h}$ over the street canyons. At a higher elevation $z>4 h, \sigma_{w}$ diminishes implying rather poor vertical mixing over the near-roof region. Differing slightly from the LES of Liu and Barth (2002), the current calculated $\sigma_{w}$ peaks near the windward corner instead of the centre of the roof level of the 

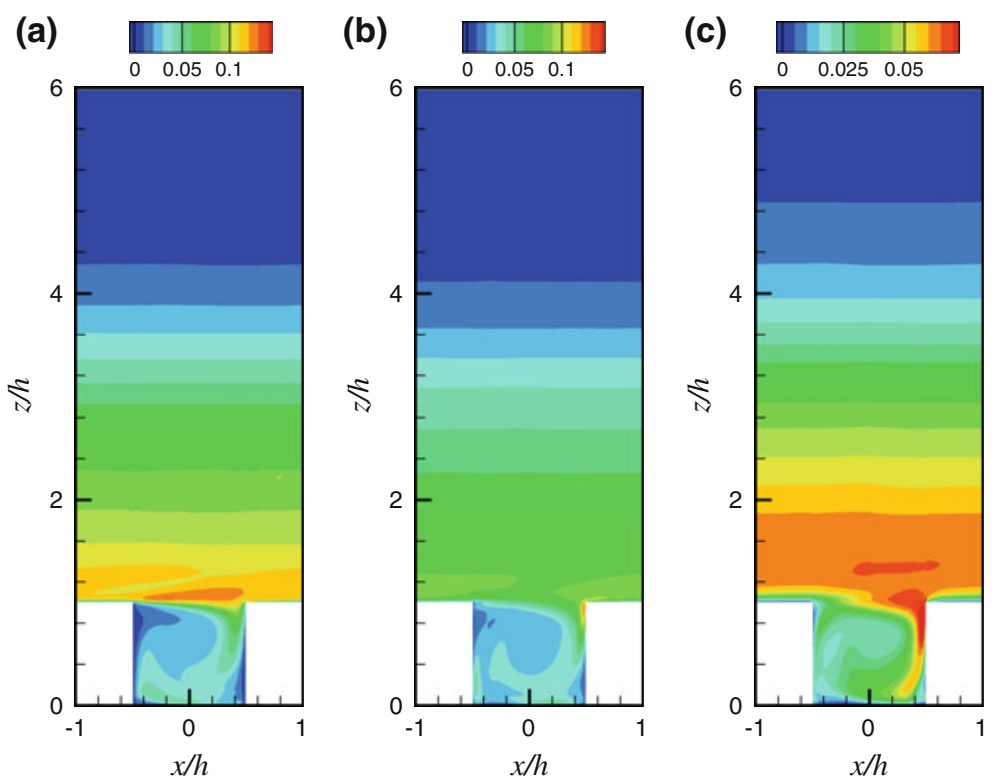

Fig. 8 Contours of $\mathbf{a} \sigma_{u} / U_{f}, \mathbf{b} \sigma_{v} / U_{f}$ and $\mathbf{c} \sigma_{w} / U_{f}$

street canyon, which is likely caused by the different shear-layer thicknesses adopted in the two LES.

Apparently, the roof-level turbulence in the street canyons is anisotropic and cannot be fully described by the normal distribution. Therefore, the $k-\varepsilon$ turbulence models, which model all turbulence scales by the eddy-viscosity approach, should be applied with caution in air pollution problems in street canyons and urban areas.

Consolidating the data from various field campaigns, Roth (2000) found that $\sigma_{i}$ are rather uniform, $\sigma_{u}=2.4 u_{*}, \sigma_{v}=1.91 u_{*}$ and $\sigma_{w}=1.27 u_{*}$, in the urban roughness sublayer. Similarly, Macdonald et al. (2002) found that $\sigma_{u}=2.1 u_{*}, \sigma_{v}=1.65 u_{*}$ and $\sigma_{w}=1.2 u_{*}$ in the roughness sublayer over an array of obstacles in a wind tunnel, in which the lower $\sigma_{i}$ are mainly due to the lack of background atmospheric turbulence at the laboratory scale. In view of the consistent pattern in various field and wind-tunnel measurements, $\sigma_{i} / u_{*}$ of the current LES data are determined along the vertical centreline $x / b=0$, and the local friction velocity $u_{*}$ is calculated by

$$
u_{*}=\sqrt{-\left\langle u^{\prime \prime} w^{\prime \prime}\right\rangle+\left\langle\left(v+v_{S G S}\right) \frac{\partial \bar{u}}{\partial z}\right\rangle} .
$$

The SGS and molecular-scale shear stresses are both taken into account in Eq. (12). It is noteworthy that the molecular-scale processes are essentially equal to zero except very close to the solid boundaries. In the shear layer $h<z<4 h, \sigma_{u} / u_{*}$ and $\sigma_{v} / u_{*}$ scatter, respectively, around 1.8 and 1.3 (Fig. 9). The discrepancy of the velocity standard deviations for $z \geq 4 h$ is largely caused by the underpredicted $u_{*}$ in the situation of a lack of background atmospheric turbulence. Although the current LES tends to underpredict $\sigma_{u} / u_{*}$ and $\sigma_{v} / u_{*}$, its profile of $\sigma_{w} / u_{*}$ is comparable to that measured in Macdonald et al. (2002), with values around 1.25 and increasing gradually with height for $z>2 h$. Obviously, one of the reasons is the use of 2D idealized street canyons in the current LES versus 3D cubes in Macdonald et al. 


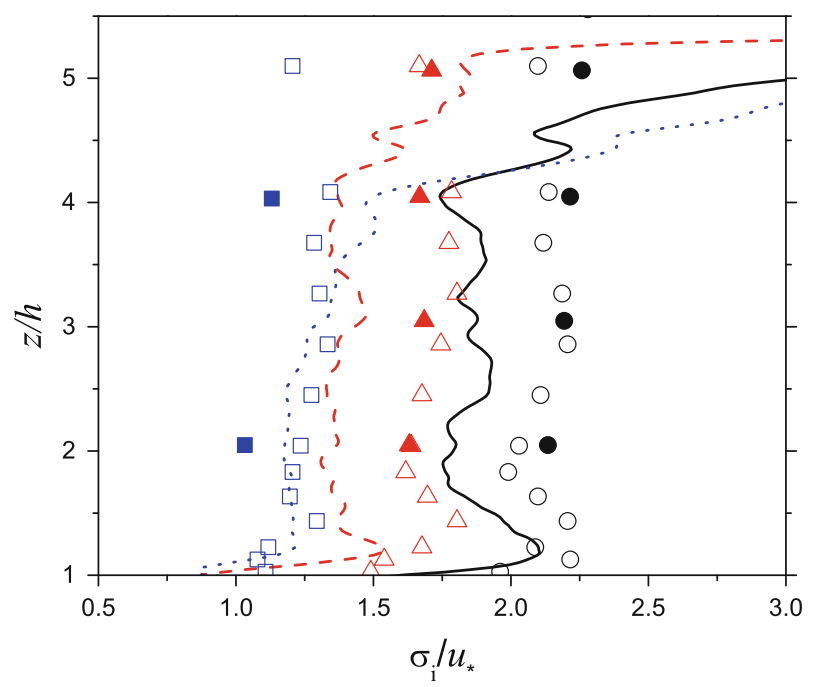

Fig. 9 Vertical profiles of $\sigma_{u} / u_{*}, \sigma_{v} / u_{*}$ and $\sigma_{w} / u_{*}$. Current LES: Black solid line $\left(\sigma_{u} / u_{*}\right)$, red dashed line $\left(\sigma_{v} / u_{*}\right)$, and blue dotted line $\left(\sigma_{w} / u_{*}\right)$; Macdonald et al. (2002): empty circle $\left(\sigma_{u} / u_{*}\right)$, empty triangle $\left(\sigma_{v} / u_{*}\right)$, and empty square $\left(\sigma_{v} / u_{*}\right)$; Duchêne-Marullaz $(1975,1979)$ : filled circle $\left(\sigma_{u} / u_{*}\right)$, filled triangle $\left(\sigma_{v} / u_{*}\right)$, and filled square $\left(\sigma_{v} / u_{*}\right)$

(2002). This difference in building geometry definitely changes the flow and the turbulence in the shear layer. Besides, isothermal conditions were assumed in the current LES in which the turbulence is only produced by mechanical shear. This mechanism differs from that in the field measurements or the wind-tunnel experiment in which other turbulence generation mechanisms (e.g. background atmospheric turbulence and turbulence spires) were used to replicate the background atmospheric turbulence. Finally, it is noteworthy that $\sigma_{v} / u_{*}$ and $\sigma_{w} / u_{*}$ have a similar magnitude in the current LES but not in Roth (2000) and Macdonald et al. (2002), which is believed to be a characteristic of the 2D street canyon being considered in the current study. The homogeneous spanwise direction reduces the respective turbulence production so the crosswind fluctuating velocities are comparable in the shear layer. Anyway, a detailed TKE budget analysis is necessary to elucidate the correlation quantitatively.

\subsection{Vertical Momentum Flux $\left\langle u^{\prime \prime} w^{\prime \prime}\right\rangle$}

The resolved-scale vertical momentum flux $\left\langle u^{\prime \prime} w^{\prime \prime}\right\rangle$ plays a major role in the momentum transport. To elucidate the momentum transport mechanism (Table 2), quadrant analysis

Table 2 Quadrants of the vertical momentum flux $\left\langle u^{\prime \prime} w^{\prime \prime}\right\rangle$

\begin{tabular}{ll}
\hline Quadrants & Directions \\
\hline Outward interactions & $u^{\prime \prime}>0, w^{\prime \prime}>0$ \\
Ejections & $u^{\prime \prime}<0, w^{\prime \prime}>0$ \\
Inward interactions & $u^{\prime \prime}<0, w^{\prime \prime}<0$ \\
Sweeps & $u^{\prime \prime}>0, w^{\prime \prime}<0$
\end{tabular}




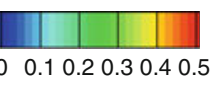

(a)

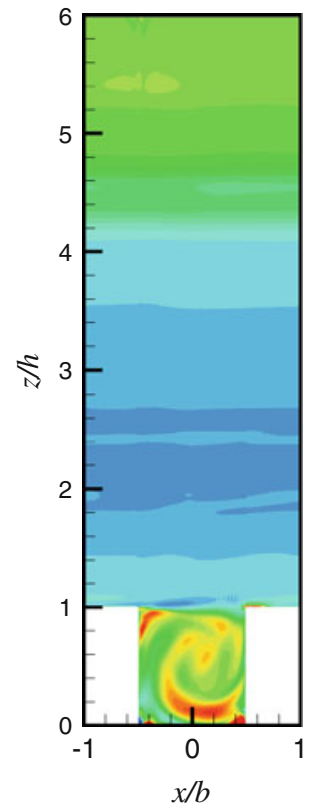

(b)

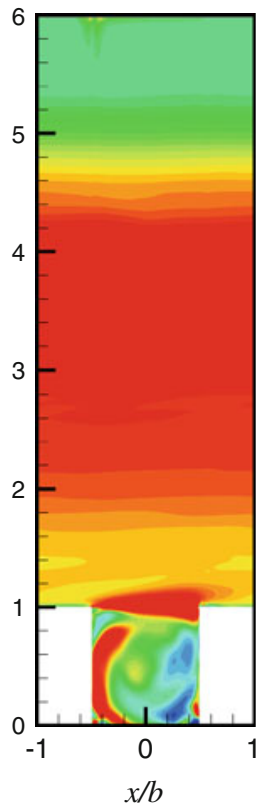

(c)

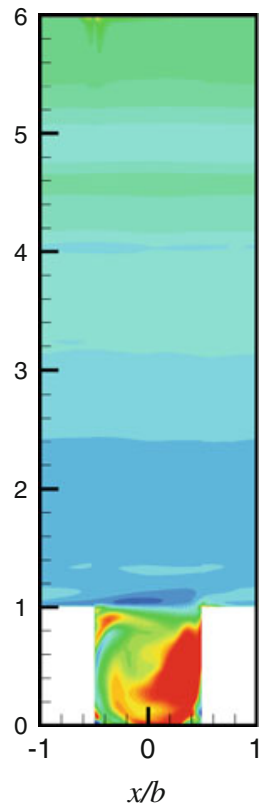

(d)

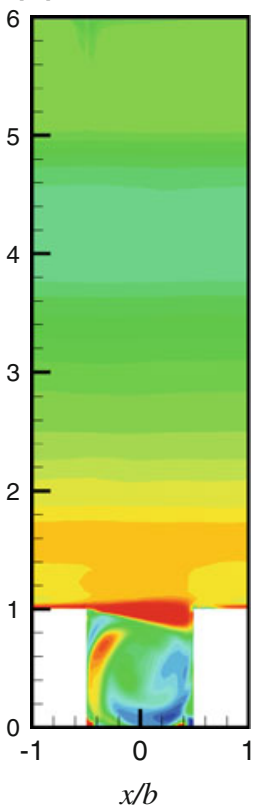

Fig. 10 Quadrant analysis of the vertical momentum flux $\left\langle u^{\prime \prime} w^{\prime \prime}\right\rangle / U_{f}^{2}$. Relative magnitudes of a outward interactions; b ejections; $\mathbf{c}$ inward interactions; and $\mathbf{d}$ sweeps

(Wallace et al 1972; Lu and Willmarth 1973; Nakagawa and Nezu 1977) is employed to partition the current LES-calculated $\left\langle u^{\prime \prime} w^{\prime \prime}\right\rangle$ (Fig. 10). The resolved-scale upward momentum transport is dominated by ejections $(>50 \%)$ and sweeps $(30 \%)$ in the shear layer while inward and outward interactions have only minor contributions $(\approx 10 \%)$. The flux $\left\langle u^{\prime \prime} w^{\prime \prime}\right\rangle$ peaks at the roof level and is dominated by sweeps and ejections, while inward and outward interactions are negligible. The vertical momentum transport is more complex in the street canyons, with inward interactions and ejections dominating on the windward and leeward sides, respectively. On the windward side, the inward interaction contributes to the downward momentum transport from the windward wall to the centre street canyon. The momentum entrained from the shear layer is then transported to the other regions of the street canyon driving the primary recirculation. On the leeward side, the mean flow is moving upwards, and the quadrant patterns are similar to the boundary-layer flow where ejections and sweeps transfer the upward momentum to the (leeward) near-wall region.

A field campaign in Zürich showed that, while the inward and outward interactions exhibit nearly the same magnitudes, the sweeps contribute slightly over the ejections both above (up to $1.5 \mathrm{~h}$ ) and below the roof level of street canyons (Rotach 1993). Similarly, a field campaign in Sapporo found that the contributions from the inward and outward interactions are about the same in the shear layer ( $6 h<z<7 h$; Oikawa and Meng 1995). In contrast to Rotach (1993), the ejections are found to contribute slightly more than the sweeps. The vertical momentum flux determined in Oikawa and Meng (1995), Macdonald et al. (2002) and the 

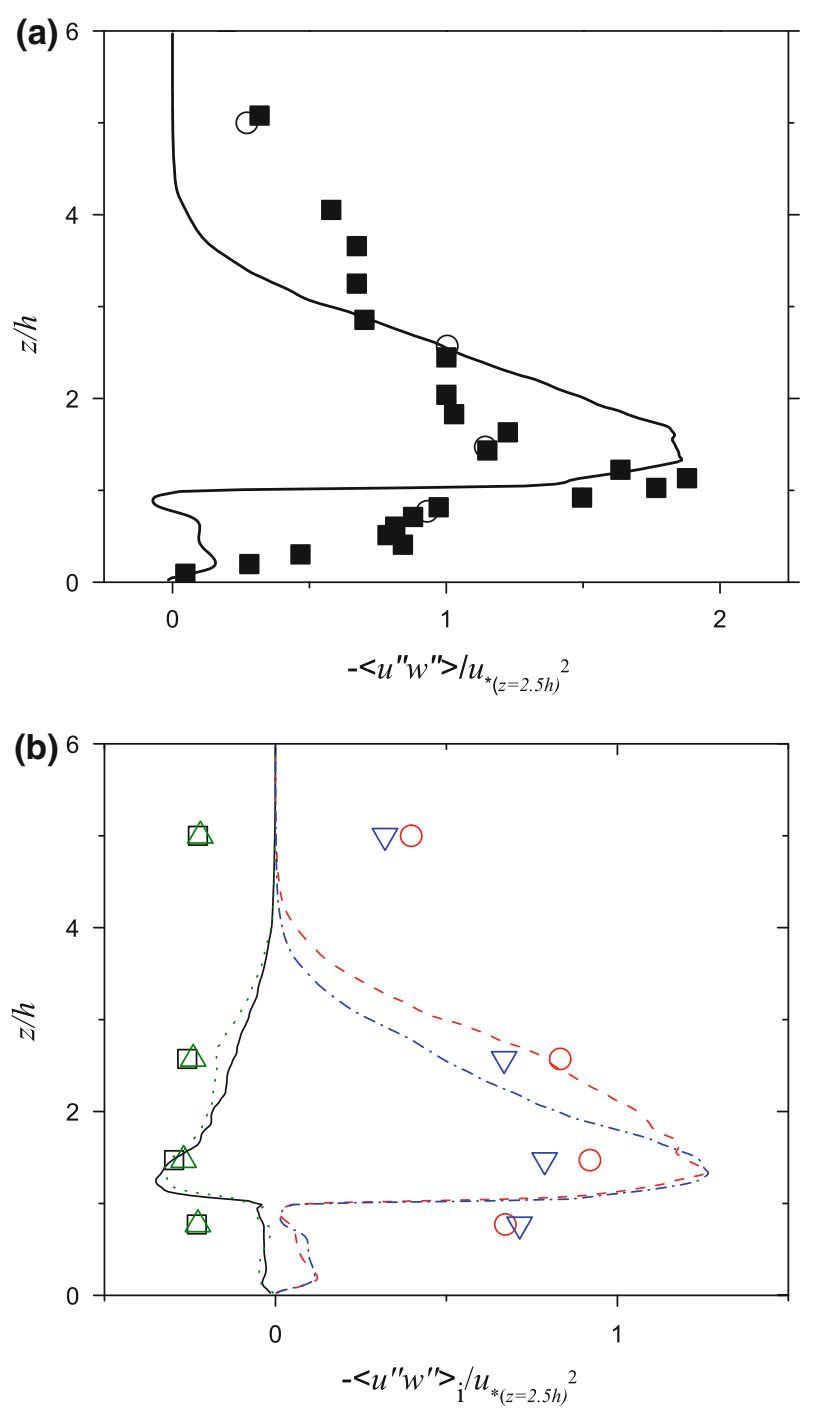

Fig. 11 Vertical profiles of a vertical momentum flux $\left\langle u^{\prime \prime} w^{\prime \prime}\right\rangle / u_{*}^{2}$ at $x / b=0.4 h$. Current LES: black solid line; Oikawa and Meng (1995): black filled circle; and Macdonald et al. (2002): red filled circle and b quadrant components $\left\langle u^{\prime \prime} w^{\prime \prime}\right\rangle_{i} / u_{*}^{2}$ at $x / b=0.4 h$. Current LES: Black solid line (outward interaction), red dashed line (ejections), green dotted line (inward interaction) and blue dash dot line (sweeps); Oikawa and Meng (1995): Black square (outward interaction), red circle (ejections), green triangle (inward interaction) and blue inverted triangle (sweeps)

current LES are compared in Fig. 11. In the current LES, $u_{*}$ is calculated at $z=2.5 \mathrm{~h}$ similar to Oikawa and Meng (1995) but the $\left\langle u^{\prime \prime} w^{\prime \prime}\right\rangle$ profile is traced at $0.1 h$ downwind of the building to avoid unnecessary building-induced over fluctuations in each quadrant. Unlike the field and wind-tunnel results, the current LES-calculated $\left\langle u^{\prime \prime} w^{\prime \prime}\right\rangle$ vanishes at about $z=5 h$. This discrepancy, similar to $\sigma_{i}$, is partly attributed to the idealized building geometry and 

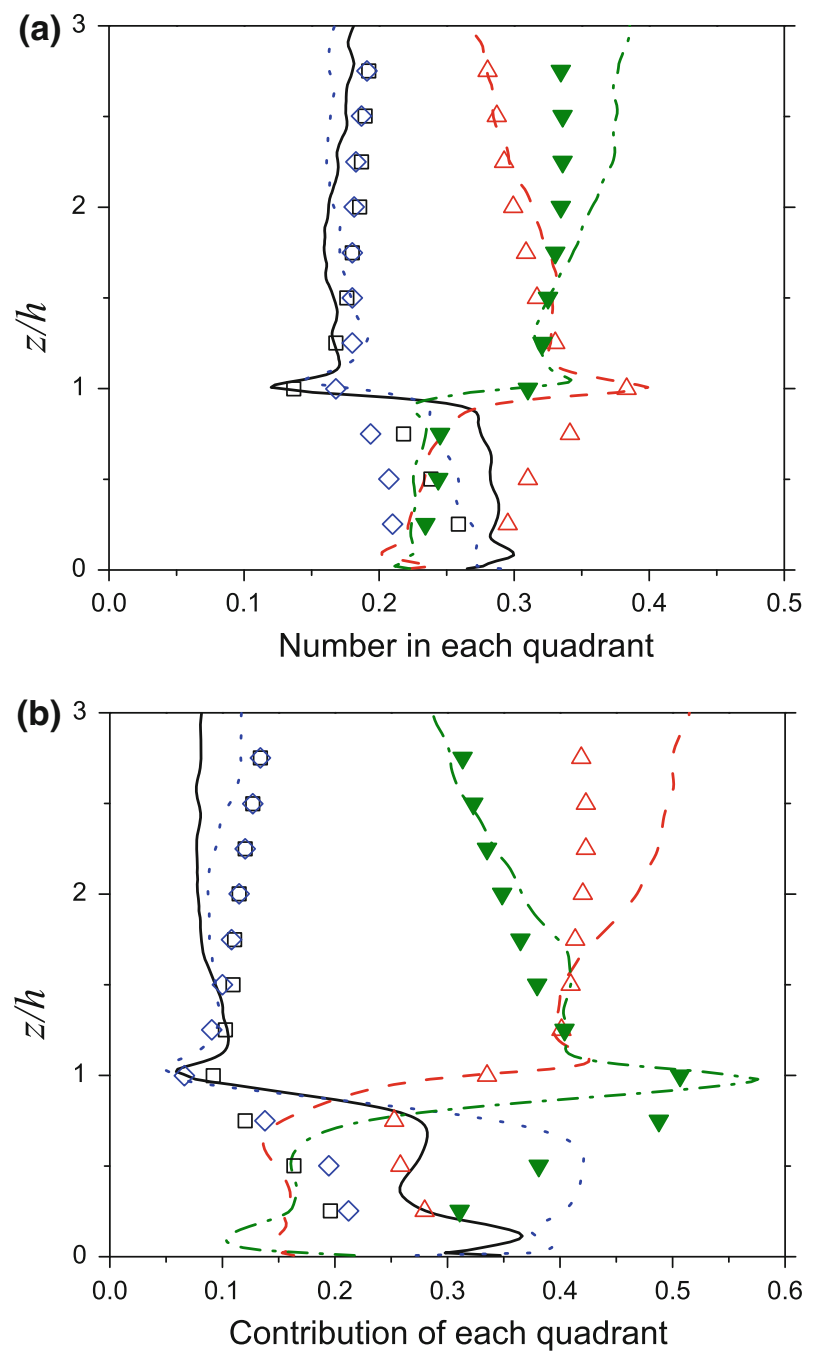

Fig. 12 Vertical profiles of a relative number and $\mathbf{b}$ relative contribution to $\left\langle u^{\prime \prime} w^{\prime \prime}\right\rangle$ of events in each quadrant. Current LES: Black solid line (outward interactions), red dashed line (ejection), blue dotted line (inward interaction), green dash dot line (sweeps); Coceal et al. (2007): Black square (outward interactions), red triangles up (ejections), blue diamonds (inward interaction), green filled triangle down (sweeps)

the horizontal periodic boundaries employed. Besides, the background large-scale atmospheric turbulence is not accounted for in the current finite LES domain that would further underpredict the turbulent transport. Nevertheless, a consistent pattern, sweeps and ejections contributing more than inward and outward interactions, is illustrated in the shear layer over $2 \mathrm{D}$ street canyons.

In addition to the comparison with field measurements, the vertical profiles of relative occurrence and contribution of each quadrant are compared with the direct numerical simulation (DNS) results of Coceal et al. (2007) (Fig. 12). The number and contribution of the quadrants are averaged in the horizontal directions similar to Coceal et al. (2007). The current 
LES results agree well with those of Coceal et al. (2007) in the shear layer in which sweeps and ejections dominate the momentum flux transport. Right over the roof level, the sweeps and ejections show almost the same number of occurrences and contributions. At a higher elevation, ejections switch to dominate the vertical momentum flux transport though sweeps occur more frequently. At the same time, inward and outward interactions contribute about the same with increasing elevation in the domain.

The major difference between the results of the current LES and the DNS of Coceal et al. (2007) is found inside the street canyons. The 2D idealized street canyons adopted in the current LES facilitate the formation of a persistent primary recirculation in skimming flow regimes while the 3D cubes in Coceal et al. (2007) do not. In view of the geometric difference, ejections have the largest number of occurrence and sweeps dominate the contribution below the roof level in the DNS. On the other hand, inward interactions dominate both the number and contribution in the street canyons in the current LES. Downward momentum transfer near the windward wall in 2D street canyon is the major reason (Fig. 10).

\subsection{Two-Point Correlations}

It is shown previously that the height of the computational domain greatly affects wind statistics in the street canyons. To determine the necessary domain size, the two-point correlation

$$
R_{\phi, x_{i}}\left(\mathbf{r}, \delta x_{i}\right) \equiv \frac{\left\langle\phi^{\prime \prime}(\mathbf{r}) \phi^{\prime \prime}\left(\mathbf{r}+\delta x_{i}\right)\right\rangle}{\sigma_{\phi}(\mathbf{r}) \sigma_{\phi}\left(\mathbf{r}+\delta x_{i}\right)}
$$

is examined where $\phi(=u, v$ or $w)$ is the variable under consideration, $\mathbf{r}$ is the position vector of the reference point, and $\delta x_{i}$ is the separation between the points in the $x_{i}$ direction. $R_{\phi, x_{i}}$ are calculated in the streamwise $\left(R_{\phi, x}\right)$, spanwise $\left(R_{\phi, y}\right)$ and vertical $\left(R_{\phi, z}\right)$ directions. The $x$ coordinate of $\mathbf{r}$ is stationary at $x / b=0$ while the $z$ coordinate is at four levels, $z / h=1.5,2,2.5$ and 3, over the street canyons (Fig. 13). The two-point correlations in the $x$ and $y$ directions change mildly at different levels, with $R_{u, x}$ falling to 0.2 at half the domain length ( $=3 h$ ) while $R_{u, y}$ attains a minimum of -0.25 then rebounds to 0.2 at half the spanwise extent $(=2.5 h)$. A few minor differences are found due to the different building geometry, for example, $R_{u, x}$ falls to 0.2 at $\delta x=6 h$ and $R_{u, y}$ falls to -0.25 at $\delta y=2.8 h$ for the flows over an array of staggered 3D cubes. Nevertheless, the LES-calculated $R_{\phi, x_{i}}$ behaviours are generally in line with those of the wind-tunnel experiment (Castro et al. 2006) and with DNS (Coceal et al. 2007).

In the horizontal directions, a similar pattern of $R_{v, x}, R_{v, y}, R_{w, x}$ and $R_{w, y}$ is found in the current LES. $R_{v, x}$ and $R_{v, y}$ diminish at $\delta x_{i}=h$ while $R_{w, x}$ and $R_{w, y}$ at $\delta x_{i}=0.5 h$, suggesting the longer integral length scale at a higher elevation. For $R_{v, x_{i}}$ and $R_{w, x_{i}}$, the increase in integral length scale is $0.5 h$ when the elevation is changed from $1.5 h$ to $3 h$, which qualitatively agrees with Castro et al. (2006).

The streamwise velocity in the shear layer shows a non-zero correlation with that in street canyons. A negative two-point correlation $(-0.2)$ is observed at the street and roof level while a positive value (0.2) is observed at the centre of the street canyon. $R_{u, z}$ decreases only slightly in magnitude with rising reference position, implying that the flows in the street canyons are coupled to those in the shear layer even at $z=3 h$. On the contrary, the twopoint correlations of $v$ and $w$ in the street canyons are reduced down to zero, implying rather uncoupled flows in the crosswind. 

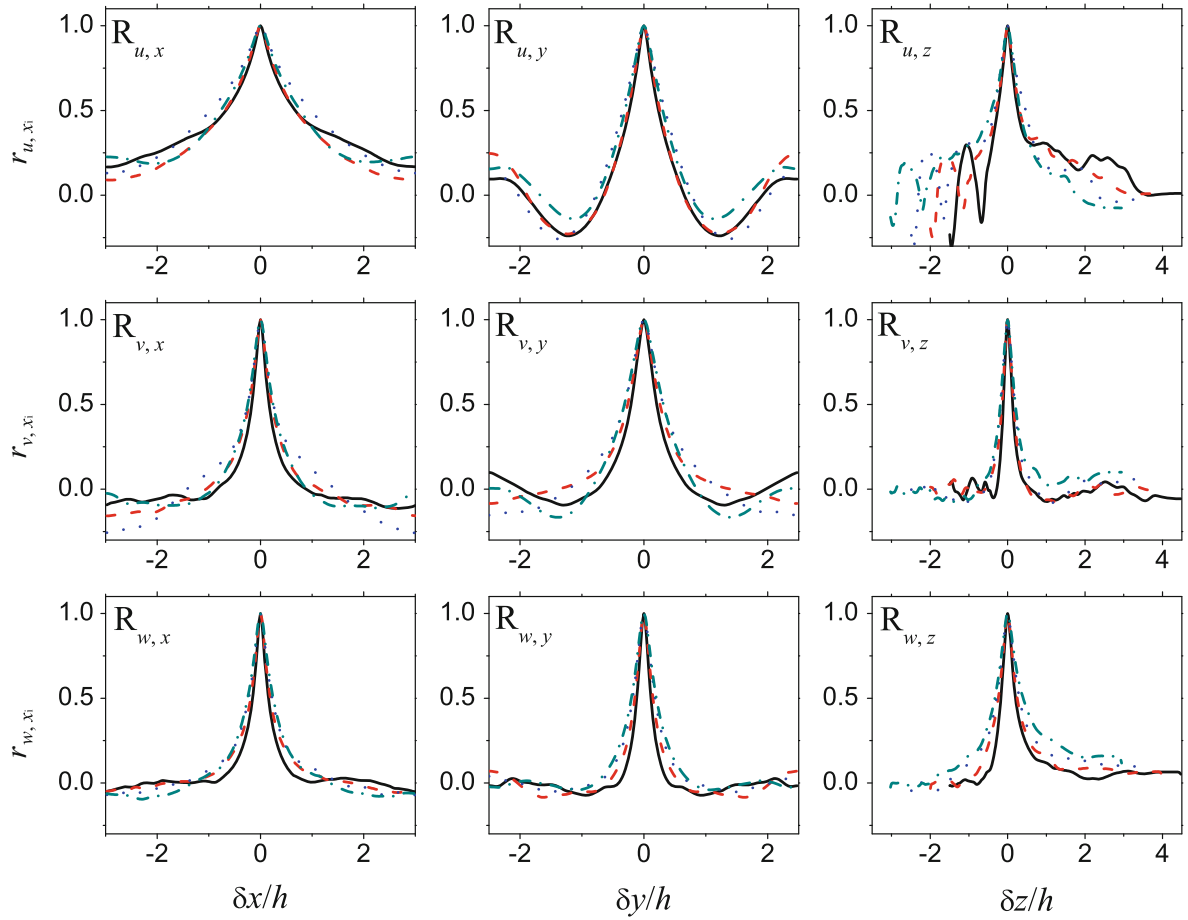

Fig. 13 Two-point correlations $R_{u_{i}, x_{i}}$ at height 1.5h: black solid line; $2 h$ : red dashed line; $2.5 h$ : blue dotted line; and 3 : green dash-dot line

\section{Pollutant Transport}

\subsection{Model Validation}

The current LES-calculated pollutant transport is validated by wind-tunnel measurements (Meroney et al. 1996; Pavageaus 1996; Pavageau and Schatzmann 1999) and other LES results (Liu et al. 2005). The effective working section of the wind tunnel is $1 \mathrm{~m}$ high, $1.5 \mathrm{~m}$ wide and $4 \mathrm{~m}$ long, and the dimensions of the 2D street canyon are $0.06 \mathrm{~m} \times 0.06 \mathrm{~m}$ in which 19-20 and 7-8 identical street canyons are placed, respectively, upstream and downstream of the sampling street canyon. The wind speed in the shear layer is $2-3 \mathrm{~m} \mathrm{~s}^{-1}$. A continuous line source (mixture of air and ethane) placed at the bottom of the test street canyon is used to simulate vehicular emission. The LES setting of Liu et al. (2005) is the same as that in Liu and Barth (2002). A ground-level continuous pollutant line source with no background pollutant is considered. An open boundary for pollutant is adopted at the outlet.

The vertical profiles of the normalized pollutant concentration $\langle\bar{c}\rangle U_{f} h L / \dot{Q}$ along the leeward and windward facades from different studies are compared in Fig. 14. Here, $L$ is the length of the pollutant line source and $\dot{Q}$ the pollutant emission rate. The current LEScalculated pollutant concentration falls within various measurement and modelling data. In contrast to Liu et al. (2005) a minimum of pollutant concentration is observed at street level. The isolated nature of the ground-level secondary recirculations drags the pollutant transport into the windward and leeward corners leading to the sharp drop in street-level pollutant concentration. Besides, a higher pollutant concentration is observed along the leeward wall 


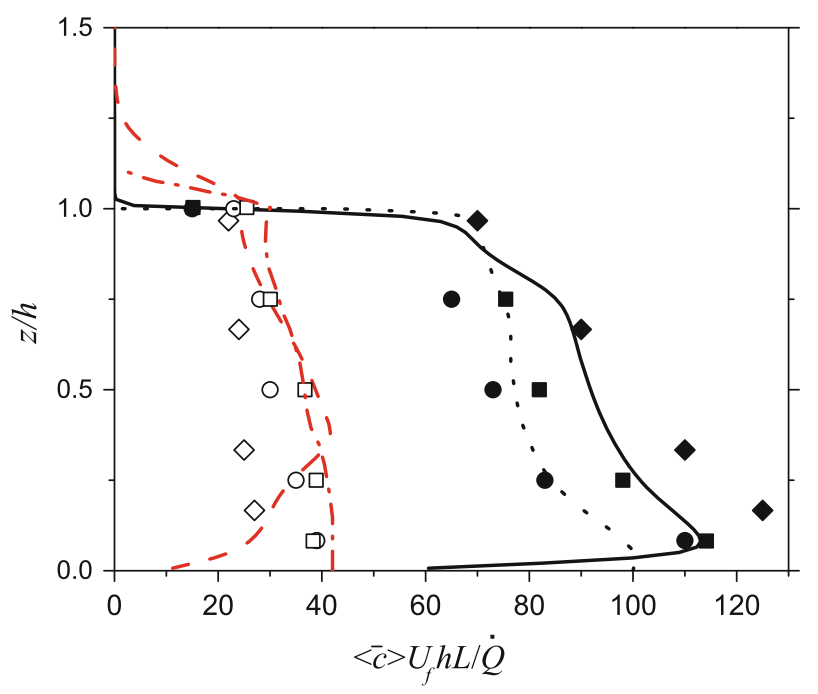

Fig. 14 Dimensionless pollutant concentration $\langle\bar{c}\rangle U_{f} h L / \dot{Q}$ on the windward and leeward walls of a street canyon of aspect ratio $h / b=1.0$. On the windward wall: current LES: dashed line; Liu et al. (2005): dashed dotted line; Pavageaus (1996): open square; Meroney et al. (1996): open diamond; Pavageau and Schatzmann (1999): open circle. On the leeward wall: current LES: Solid line; Liu et al. (2005): dashed line; Pavageaus (1996): filled square; Meroney et al. (1996): filled diamond; Pavageau and Schatzmann (1999): filled circle

compared with that in Liu et al. (2005), which could be a result of a higher recirculating flow speed in the shallow domain in Liu et al. (2005). Nonetheless, the current LES-calculated result agrees reasonably well with that of wind-tunnel measurements and previous LES, demonstrating its accuracy for pollutant transport calculation in street canyons.

\subsection{Pollutant Concentration and Standard Deviation}

The spatial contours of the mean pollutant concentration $\langle\bar{c}\rangle$ and the standard deviation of pollutant concentration $\sigma_{c}$ are depicted in Fig. 15. Pollutant trapping is found inside the street canyons developing a large pollutant concentration difference between the shear layer and the street level. The pollutant concentration in the street canyons is rather uniform $\left(0.2 C_{0}\right)$ except that a lower value is observed near the windward facade, suggesting that fresh air is drawn in on the windward side to promote the pollutant mixing inside the street canyons. Only a shallow layer $(<1.1 \mathrm{~h})$ of pollutant is developed over the roof level so less pollutant is carried upward into the shear layer (Fig. 15a). Pollutant entrainment also leads to higher pollutant concentrations in the street canyons locating further downwind.

Peaks of $\sigma_{c}$ are observed at the roof and ground levels of the street canyons (Fig. 15b), with the roof-level peaks induced by the locally intense turbulence promoting pollutant mixing. The ground-level turbulence is weak but the pollutant concentration is higher, thus, even a small turbulence intensity could induce a large fluctuation in $\bar{c}$. In the street canyons located downwind, $\sigma_{c}$ decreases slightly at roof level and at the centre of the street canyons, which could be caused by the lower roof-level vertical pollutant concentration gradient as a result of the upwind pollutant. Similar to building geometry, isolated and periodic pollutant configurations result in different pollutant transport behaviours. 

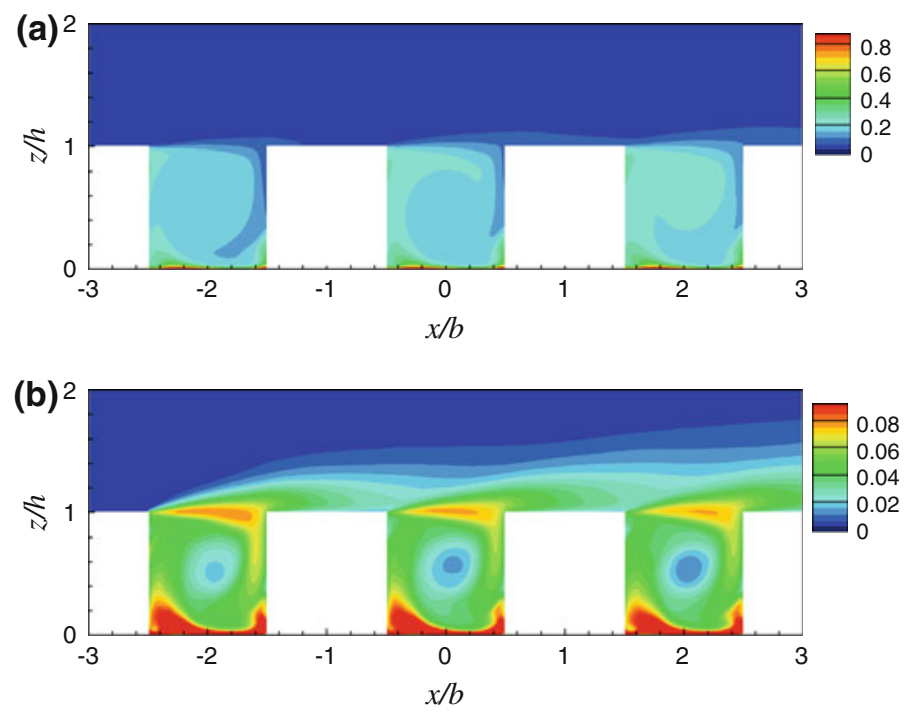

Fig. 15 Contours of a pollutant concentration $\langle\bar{c}\rangle / C_{0}$ and $\mathbf{b}$ standard deviation of pollutant concentration $\sigma_{c} / C_{0}$

Table 3 Quadrants of the vertical pollutant flux $\left\langle c^{\prime \prime} w^{\prime \prime}\right\rangle$

\begin{tabular}{ll}
\hline Quadrants & Directions \\
\hline Ejections & $c^{\prime \prime}>0, w^{\prime \prime}>0$ \\
Outward interactions & $c^{\prime \prime}<0, w^{\prime \prime}>0$ \\
Sweeps & $c^{\prime \prime}<0, w^{\prime \prime}<0$ \\
Inward interactions & $c^{\prime \prime}>0, w^{\prime \prime}<0$ \\
\hline
\end{tabular}

Table 4 Average pollutant concentration $\Phi$ and convective transfer coefficient $\Omega_{T}$ of the pollutant

\begin{tabular}{llllll}
\hline Results & $\Phi / C_{0}$ & $\Omega_{T}$ & $\Omega_{T+}$ & $\Omega_{T-}$ & $\Omega_{T-} / \Omega_{T+}$ \\
\hline Current LES, 1st canyon & 0.190 & 0.00232 & 0.00314 & -0.00083 & $26.3 \%$ \\
Current LES, 2nd canyon & 0.205 & 0.00210 & 0.00344 & -0.00134 & $38.9 \%$ \\
Current LES, 3rd canyon & 0.217 & 0.00213 & 0.00375 & -0.00163 & $43.3 \%$ \\
Barlow et al. (2004), wind tunnel & & 0.00192 & & & \\
Cai et al. (2008), LES & & 0.00179 & & & \\
\hline
\end{tabular}

\subsubsection{Average Pollutant Concentration $\Phi$}

In order to investigate how the pollutant is transported downstream, the average pollutant concentration in a street canyon

$$
\Phi=\frac{1}{V_{\text {canyon }}} \int_{\text {canyon }}\langle\bar{c}\rangle \mathrm{d} V
$$

is calculated and tabulated in Table 4. Here, $V_{\text {canyon }}$ is the volume of the street canyon. As expected, $\Phi$ increases in the streamwise direction because of the upwind pollutants. In the first street canyon, there is no background pollutant and $\phi$ is equal to $0.19 C_{0}$, while in the 
second street canyon, the pollutant concentration is raised by the upwind pollutant, and a higher $\Phi\left(=0.205 C_{0}\right)$ is thus obtained. Analogously, the pollutant emitted from both the first and second street canyons collectively contributes to the resultant pollutant concentration, and even higher $\Phi\left(=0.217 C_{0}\right)$ is observed in the last street canyon. The pollutant removal and re-entrainment in the downstream street canyon are detailed in Sect. 4.4.

\subsection{Quadrant Analysis of the Vertical Turbulent Pollutant Flux $\left\langle c^{\prime \prime} w^{\prime \prime}\right\rangle$}

Analogous to the quadrant analysis of $\left\langle u^{\prime \prime} w^{\prime \prime}\right\rangle$, the vertical component of the turbulent pollutant flux $\left\langle c^{\prime \prime} w^{\prime \prime}\right\rangle$ is partitioned into four quadrants depending on the signs of $w^{\prime \prime}$ and $c^{\prime \prime}$ (Table 3; Chen 1990; Katul et al. 1997; Katsouvas et al. 2007). In contrast to the downward-moving $\left\langle u^{\prime \prime} w^{\prime \prime}\right\rangle$, the pollutant emitted at the street level is carried upward. At the roof level, where the vertical mean velocity is small, sweeps (ejections) indicate the amount of fresh-air entrainment into (aged air leaving) the street canyons to the shear layer. The current LES results show that the ejections and sweeps are the dominating components of $\left\langle c^{\prime \prime} w^{\prime \prime}\right\rangle$, while the inward and outward interactions only play minor roles (Fig. 16). In particular, the sweeps contribute slightly more over the ejections, though their contour values are similar and their peaks overlap at the roof level of the street canyons. Apart from the roof level, sweeps are observed near the windward facade denoting strong fresh-air entrainment, caused by the localized turbulence production when the prevailing flow impinges on the windward buildings, that in turn enhances the pollutant mixing. As illustrated in Figs. 8 and 16, the turbulence produced at the windward roof level is able to penetrate down to the ground. The collective effect of turbulence production and primary circulation leads to well-mixed pollutant inside the street canyons (Fig. 15a). The three street canyons exhibit almost the same pattern of quadrant component, suggesting that the pollutant sources upstream or downstream do not affect too much the pollutant dispersion mechanism. The only notable change is the weakened roof-level ejections and sweeps in the downwind street canyons, which is likely attributed to the upwind pollutant together with the reduced vertical pollutant concentration gradient.

\subsection{Convective Transfer Coefficient $\Omega_{T}$}

The convective transfer coefficient of a pollutant

$$
\Omega_{T}=\frac{1}{h C_{0} U_{f}} \int_{\text {roof }}\langle\bar{c} \bar{w}\rangle \mathrm{d} x,
$$

which was defined in Barlow and Belcher (2002), is calculated for the street canyons individually using the current LES data. In fact the normalized pollutant removal rate measuring the average amount of pollutant being removed across the roof level out of the street canyon per unit time. It is found that the first street canyon exhibits the largest $\Omega_{T}$ while the second and the third canyons have nearly the same values (Table 4). Hence, the current LES results signify that, for a street canyon under the influence of upwind or ambient pollutants, the difference in pollutant concentration between the shear layer and the street canyon cannot be calculated only by the ground-level pollutant concentration. Moreover, the assumption of rapid dilution should be applied with caution. Since the current LES consists of only two downwind street canyons, it is not comprehensive enough for testing other proposals on the calculation of the pollutant concentration difference. The methodology proposed by Barlow and Belcher (2002) is therefore retained in our calculation of $\Omega_{T}$. 

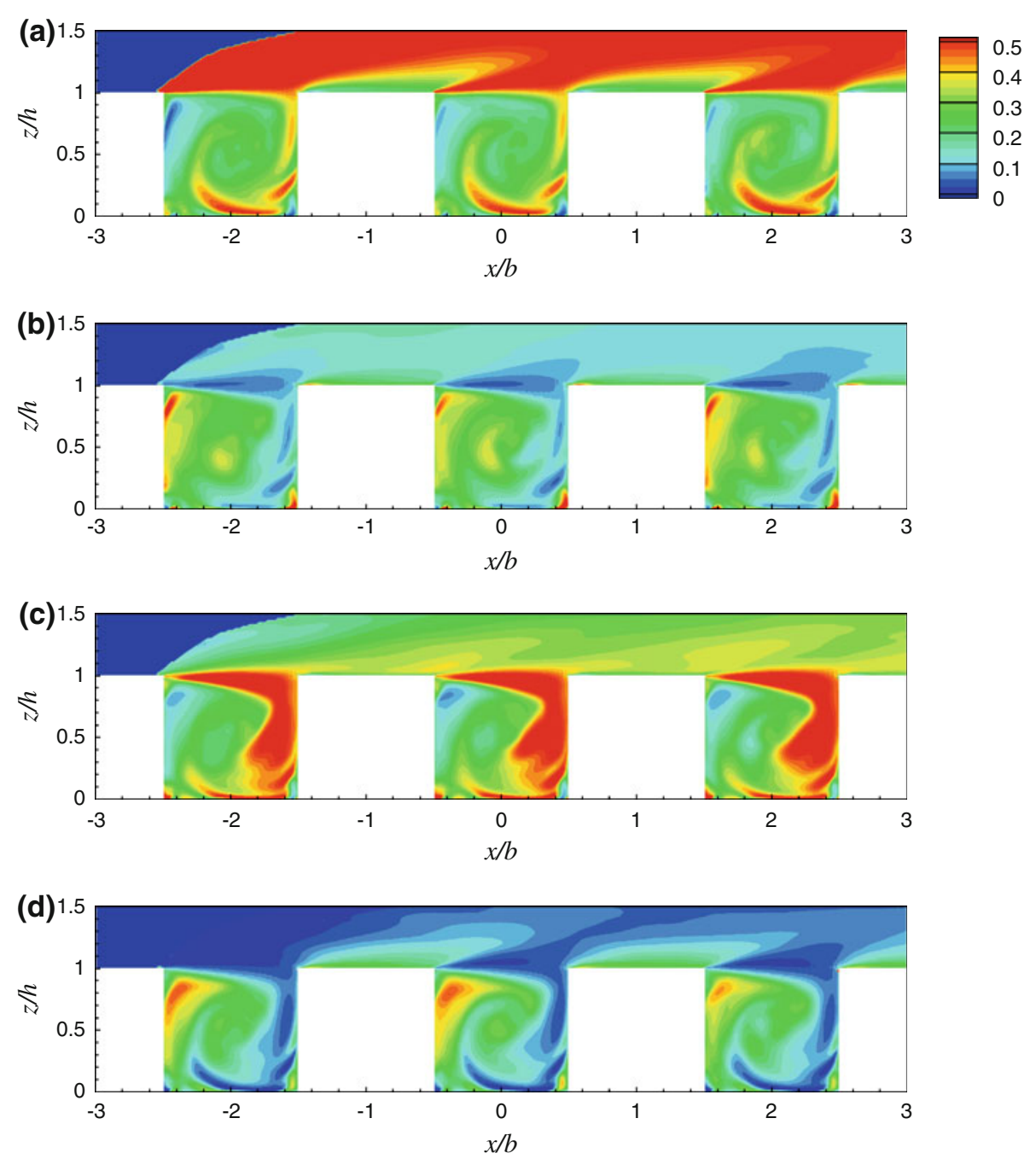

Fig. 16 Quadrant analysis of the vertical turbulent pollutant flux $\left\langle w^{\prime \prime} c^{\prime \prime}\right\rangle$. Relative magnitudes of a ejections; b outward interactions; c sweeps; and $\mathbf{d}$ inward interactions

To examine the pollutant removal and re-entrainment in detail, we further partition $\Omega_{T}$ into the removal $\left(\Omega_{T+}\right)$ and re-entrainment $\left(\Omega_{T-}\right)$ components. Mathematically

$$
\begin{aligned}
& \Omega_{T+}=\frac{1}{h C_{0} U_{f}} \int_{\text {roof }}\left\langle\bar{c} \bar{w}_{+}\right\rangle \mathrm{d} x, \\
& \Omega_{T-}=\frac{1}{h C_{0} U_{f}} \int_{\text {roof }}\left\langle\bar{c} \bar{w}_{-}\right\rangle \mathrm{d} x,
\end{aligned}
$$

where 


$$
\begin{aligned}
& \bar{w}_{+}= \begin{cases}\bar{w} & \text { if } \bar{w} \geq 0, \\
0 & \text { if } \bar{w}<0 .\end{cases} \\
& \bar{w}_{-}= \begin{cases}\bar{w} & \text { if } \bar{w} \leq 0, \\
0 & \text { if } \bar{w}>0 .\end{cases}
\end{aligned}
$$

$\Omega_{T+}$ is found to increase from 0.00314 to 0.00344 then 0.00375 in the streamwise direction (Table 4), implying that the pollutant is removed more efficiently from the street canyons downwind. On the other hand, $\Omega_{T}$ - decreases from -0.00083 to -0.00134 then finally -0.00163 , implying that more pollutant re-enters from the shear layer into the street canyons. These variations in $\Omega_{T+}$ and $\Omega_{T-}$ signify that, in analogy to the average pollutant concentration, pollutant removal and re-entrainment are not only functions of building geometry but also pollutant concentrations. Given that a constant pollutant concentration was employed on the streets in the current LES, a different amount of pollutant is emitted because of the different pollutant concentrations in the street canyons. As such, the ratio $\Omega_{T-} / \Omega_{T+}$ is tabulated in Table 4, and since there is no upwind pollutant in the first street canyon, $26.3 \%$ of re-entrainment is observed. On the other hand, 38.9 and $43.3 \%$ of re-entrainments are observed, respectively, in the second and third street canyons. In view of nearly the same $\Omega_{T}$ in the two downwind street canyons, the amount of pollutant re-entrainment increases more slowly under the influence of background pollutant. Apart from dividing $\Omega_{T}$ into the removal and re-entrainment components, it can be separated into mean $(\langle\bar{u}\rangle\langle\bar{c}\rangle)$ and turbulent $\left(\left\langle u^{\prime \prime} c^{\prime \prime}\right\rangle\right)$ components. Our LES results show that the roof-level vertical mean pollutant flux is negative, contributing less than $1 \%$ to the total flux, and is therefore insignificant to the roof level pollutant removal in the skimming flow regime.

The wind-tunnel results of Barlow et al. (2004) and the LES results of Cai et al. (2008), in which the aspect ratio equals one, are also tabulated in Table 4. The experiment of Barlow et al. (2004) consisted of eight street canyons aligned in the streamwise direction after upwind roughness and fences. Naphthalene sublimation was measured in the last street canyon to study the scalar removal. On the other hand, the Smagorinsky eddy-viscosity model and area sources of constant pollutant concentration were used in the LES of Cai et al. (2008). Neither Barlow et al. (2004) nor Cai et al. (2008) considered pollutant re-entrainment so their $\Omega_{T}$ should be compared with that of the first street canyon in the current LES. A difference of $20 \%$ in $\Omega_{T}$ is observed comparing the current LES results with those of Barlow et al. (2004) and Cai et al. (2008). This could be attributed to the use of the wall model for pollutant emission in Cai et al. (2008), which more accurately resolves the early pollutant transport in the near-wall region.

\section{Conclusions}

A large-eddy simulation (LES) model with the one-equation subgrid-scale (SGS) model was developed to investigate the wind statistics and the pollutant removal in and above twodimensional (2D) idealized street canyons. A computational domain of size $6 h \times 5 h \times 6 h$, consisting of three identical street canyons of building-height-to-street-width (aspect) ratio $(h / b)$ equal to one, was employed. Comparing with other LES and water-channel results, the use of a short domain height would increase the velocity gradient in the shear layer promoting the turbulence production. It would also underestimate the free-stream velocity $U_{f}$ because the shallow shear layer limits the wind-profile development. A shear layer of depth $h$ is barely enough for reasonably accurate wind and turbulence statistics inside a street canyon. 
However, if the turbulence over the street canyon is of interest, a computational domain larger than the current one $(6 h \times 5 h \times 6 h)$ is necessary. This is depicted by the non-zero two-point correlations in the streamwise direction $R_{u, x}$ and $R_{v, x}$ even at half the domain length in the current LES.

The vertical profiles of mean wind, TKE, and velocity skewness and kurtosis are compared with previous LES, wind-tunnel, water-channel and field data. Peaks of skewness and kurtosis of the resolved-scale streamwise velocity $\bar{u}$ develop at the roof level of the street canyons, suggesting that the probability distribution of $\bar{u}$ deviates substantially from the normal distribution. The spatial contours of velocity standard deviations, $\sigma_{u}, \sigma_{v}$ and $\sigma_{w}$, show that the maximum velocity fluctuations occur at the roof-level windward corner of the street canyon. Over the street canyons in the shear layer, $\sigma_{w}$ is found to peak again at $z=1.5 \mathrm{~h}$. Based on the current LES results, the profiles of the normalized streamwise $\left(\sigma_{u} / u_{*} \approx 1.8\right)$ and spanwise $\left(\sigma_{v} / u_{*} \approx 1.3\right)$ velocity standard deviations exhibit almost uniform values in the urban roughness sublayer $(h<z<4 h)$. While $\sigma_{i}$ calculated by the current LES are smaller than those found in the wind-tunnel experiment (Macdonald et al. 2002) and field measurements (Duchêne-Marullaz 1975, 1979), the LES turbulence is only generated by mechanical shear. Other turbulence generation mechanisms, such as the background atmospheric turbulence, are not included.

Using the quadrant analysis of $\left\langle u^{\prime \prime} w^{\prime \prime}\right\rangle$, the sweeps and ejections are the dominating events, while the inward and outward interactions are small and almost completely offset each other. The two-point correlation coefficient $R_{u_{i}, x_{i}}$ in the streamwise, spanwise and vertical directions are calculated to determine the integral length scales. Non-zero $R_{u, x}(=0.2)$ at a separation of half the domain size $(3 h)$ is observed, suggesting that the domain size of the current LES may not be large enough for capturing all of the essential large-scale turbulence.

The pollutant transport was also examined. The most favourable pollutant removal takes place at the roof-level windward corner since the prevailing flow impinges on the windward building enhancing turbulence production locally. A lower pollutant concentration at the roof-level windward corner is observed compared with other regions in the street canyon. As expected, the street canyons located further downwind have higher average pollutant concentrations $\Phi$. An increase in $\Phi / C_{0}$ from 0.190 to 0.205 and then to 0.217 is observed at the street canyon located further downstream. Moreover, the convective transfer coefficient $\Omega_{T}$ of pollutant is partitioned into the removal $\left(\Omega_{T+}\right)$ and re-entrainment $\left(\Omega_{T-}\right)$ components by conditional sampling in order to quantify the pollutant re-entrainment behaviour. It is found that the ratio $\Omega_{T-} / \Omega_{T+}$ increases from $26.3 \%$, to $38.9 \%$ and then $43.3 \%$ in the street canyons in the streamwise direction as a result of pollutant re-entrainment.

Acknowledgements This project is partly supported by the University Research Committee Seed Funding Programme of Basic Research of the University of Hong Kong 200811159170. The authors are also grateful to the technical support from Mr. W.K. Kwan, Mr. Frankie T.F. Cheung and Ms. Lilian Y.L. Chan with the Computer Centre, The University of Hong Kong.

Open Access This article is distributed under the terms of the Creative Commons Attribution Noncommercial License which permits any noncommercial use, distribution, and reproduction in any medium, provided the original author(s) and source are credited.

\section{References}

Barlow JF, Belcher SE (2002) A wind tunnel model for quantifying fluxes in the urban boundary layer. Boundary-Layer Meteorol 104:131-150 
Barlow JF, Harman IN, Belcher SE (2004) Scalar fluxes from urban street canyons. Part I: Laboratory simulation. Boundary-Layer Meteorol 113:369-385

Belcher SE (2005) Mixing and transport in urban areas. Phil Trans Roy Soc A 363:2947-2968

Berkowicz R, Plamgren F, Hertel O, Vignati E (1996) Using measurements of air pollution in streets for evaluation of urban air quality-meteorological analysis and model calculations. Sci Total Environ 189(190):259-265

Brown MJ, Lawson RE, Decroix DS, Lee RL (2000) Mean flow and turbulence measurements around a 2-D array of buildings in a wind tunnel. In: Proceedings of the 11th joint AMS/AWMA conference in applied air pollution meteorology, Long Beach, CA, USA

Cai XM (2009) Differential wall heating in street canyons: flow characteristics. In: Proceedings of the 7th international conference on urban climate, Yokohama, Japan

Cai XM, Barlow JF, Belcher SE (2008) Dispersion and transfer of passive scalars in and above street canyons-large-eddy simulations. Atmos Environ 42:5885-5895

Castro IP, Cheng H, Reynolds R (2006) Turbulence over urban-type roughness: deductions from wind-tunnel measurements. Boundary-Layer Meteorol 118:109-131

Chandrasekhar S (1981) Hydrodynamic and hydromagnetic stability. Oxford University Press, U.K., 704 pp

Chen F (1990) Turbulent characteristics over a rough natural surface part I: turbulent structures. BoundaryLayer Meteorol 52:151-175

Coceal O, Dobre A, Thomas TC, Belcher SE (2007) Structure of turbulent flow over regular arrays of cubical roughness. J Fluid Mech 589:375-409

Cui ZQ, Cai XM, Baker CJ (2004) Large-eddy simulation of turbulent flow in a street canyon. Q J Roy Meteorol Soc 130:1373-1394

Duchêne-Marullaz P (1975) Full-scale measurements of atmospheric turbulence in a suburban area. In: Proceedings of the 4th international conference on wind effects on buildlings and structures, London, UK, pp 23-31

Duchêne-Marullaz P (1979) Effect of high roughness on the characteristics of turbulence in cases of strong winds. In: Preprints of the 5th international conference on wind engineering, American Meteorological Society, Boston, USA, pp 179-193

Kanda M, Moriwaki R, Kasamatsu F (2004) Large-eddy simulation of turbulent organized structures within and above explicitly resolved cube arrays. Boundary-Layer Meteorol 112:343-368

Katsouvas G, Helmis C, Wang Q (2007) Quadrant analysis of the scalar and momentum fluxes in the stable marine atmospheric surface layer. Boundary-Layer Meteorol 124:335-360

Katul G, Kuhn G, Schieldge J, Hsieh C (1997) The ejection-sweep character of scalar fluxes in the unstable surface layer. Boundary-Layer Meteorol 83:1-26

Launder BE, Spalding DB (1974) The numerical computation of turbulent flows. Comput Methods Appl Mech Eng 3:269-289

Letzel MO, Krance M, Raasch S (2008) High resolution urban large-eddy simulation studies from street canyon to neighbourhood scale. Atmos Environ 42:8770-8784

Li XX, Liu CH, Leung DYC, Lam KM (2006) Recent progress in CFD modelling of wind field and pollutant transport in street canyons. Atmos Environ 40:5640-5658

Li XX, Leung DYC, Liu CH, Lam KM (2008a) Physical modeling of flow field inside urban street canyons. J Appl Meteorol Climatol 47:2058-2067

Li XX, Liu CH, Leung DYC (2008b) Large-eddy simulation of flow and pollutant dispersion in high-aspectratio urban street canyons with wall model. Boundary-Layer Meteorol 129:249-268

Li XX, Koh TY, Britter R, Liu CH, Norford K, Entekhabi D, Leung DYC (2009) Large-eddy simulation of flow field and pollutant dispersion in urban street canyons under unstable stratifications. In: Proceedings of the 7th international conference on urban climate, Yokohama, Japan

Li XX, Britter RE, Koh TY, Norford LK, Liu CH, Entekhabi D, Leung DYC (2010) Large-eddy simulation of flow and pollutant transport in urban street canyons with ground heating. Boundary-Layer Meteorol 137:187-204

Liu CH, Barth MC (2002) Large-eddy simulation of flow and scalar transport in a modeled street canyon. J Appl Meteorol 41:660-673

Liu CH, Leung DYC, Barth MC (2004) Large-eddy simulation of flow and pollutant transport in a street canyons of different building-height-to-street-width ratios. J Appl Meteorol 43:1410-1424

Liu CH, Leung DYC, Barth MC (2005) On the prediction of air and pollutant exchange rates in street canyons of different aspect ratios using large-eddy simulation. Atmos Environ 39:1567-1574

Louka P, Belcher SE, Harrison RG (1998) Modified street canyon flow. J Wind Eng Ind Aerodyn 74-76:485493

Louka P, Belcher SE, Harrison RG (2000) Coupling between air flow in streets and the well-developed boundary layer aloft. Atmos Environ 34:2613-2621 
Lu SS, Willmarth WW (1973) Measurements of the structure of the Reynolds stress in a turbulent boundary layer. J Fluid Mech 60:481-511

Macdonald RW, Schofield SC, Slawsoon PR (2002) Physical modelling of urban roughness using arrays of regular roughness elements. Water Air Soil Pollut 2:541-554

Meroney RN, Pavageau M, Rafailidis S, Scharzmann M (1996) Study of line source characteristics for 2-D physical modelling of pollutant dispersion in street canyon. J Wind Eng Ind Aerodyn 62:37-56

Nakagawa H, Nezu J (1977) Prediction of the contributions to the Reynolds stress from bursting events in open-channel flows. J Fluid Mech 80:99-128

Nelson MA, Pardyjak ER, Klewicki JC, Pol SU, Brown MJ (2007) Properties of the wind field within the Oklahoma City Park Avenue Street canyon. Part I: Mean flow and turbulence statistics. J Appl Meteorol Climatol 46:2038-2054

Oikawa S, Meng Y (1995) Turbulence characteristics and organized motion in a suburban roughness sublayer. Boundary-Layer Meteorol 74:289-312

Oke TR (1976) The distinction between canopy and boundary-layer urban heat island. Atmos Environ 14: 268-277

Oke TR (1988) Street design and urban canopy layer climate. Energy Build 11:103-113

OpenFOAM (2009) http://www.opencfd.co.uk/openfoam/. Accessed Feb 2010

Park SB, Baik JJ (2009) LES study of thermal effects on turbulent flow and dispersion in a street canyon. In: Proceedings of the 7th international conference on urban climate, Yokohama, Japan

Pavageau M, Schatzmann M (1999) Wind tunnel measurements of concentration fluctuations in an urban street canyon. Atmos Environ 33:3961-3971

Pavageaus M (1996) Concentration fluctuations in urban street canyons-groundwork for future studies. Technical report, Meteorological Institute of the University of Hamburg, $97 \mathrm{pp}$

RAMS (2009) http://rams.atmos.colostate.edu/. Accessed Feb 2010

Rotach MW (1993) Turbulence close to a rough urban surface. Part I: Reynolds stress. Boundary-Layer Meteorol 65:1-28

Roth M (2000) Review of atmospheric turbulence over cities. Q J Roy Meteorol Soc 126:941-990

Schumann U (1975) Subgrid scale model for finite difference simulations of turbulent flows in plane channels and annuli. J Comput Phys 18:376-404

Spalding DB (1962) A new analytical expression for the drag of a flat plate valid for both the turbulent and laminar regimes. Int J Heat Mass Transf 5:1133-1138

Vardoulakis S, Fisher BE, Pericleous K, Gonzalez-Flesca N (2003) Modelling air quality in street canyons: a review. Atmos Environ 37:155-182

Wallace JM, Eckelmannm H, Brodkey RS (1972) The wall region in turbulent shear flow. J Fluid Mech 54: $39-48$ 